\title{
Role of dynamic loading on early stage of bone fracture healing
}

\author{
Smriti Ghimire ${ }^{1}$, Saeed Miramini ${ }^{1}$, Martin Richardson ${ }^{2}$, Priyan Mendis ${ }^{1}$, Lihai Zhang ${ }^{1}$ \\ ${ }^{1}$ Department of Infrastructure Engineering, University of Melbourne, Melbourne, VIC 3010, \\ Australia; ${ }^{2}$ The Epworth Hospital, Richmond, VIC 3012, Australia
}

\begin{abstract}
After fracture, mesenchymal stem cells (MSCs) and growth factors migrate into the fracture callus to exert their biological actions. Previous studies have indicated that dynamic loading induced tissue deformation and interstitial fluid flow could produce a biomechanical environment which significantly affects the healing outcomes. However, the fundamental relationship between the various loading regimes and different healing outcomes has not still been fully understood. In this study, we present an integrated computational model to investigate the effect of dynamic loading on early stage of bone fracture healing. The model takes into account cell and growth factor transport under dynamic loading, and mechanical stimuli mediated MSC differentiation and tissue production. The developed model was firstly validated by the available experimental data, and then implemented to identify the loading regimes that produce the optimal healing outcomes. Our results demonstrated that dynamic loading enhances MSC and growth factor transport in a spatially dependent manner. For example, compared to free diffusion, dynamic loading could significantly increase MSCs concentration in endosteal zone; and chondrogenic growth factors in both cortical and periosteal zones in callus. Furthermore, there could be an optimal dynamic loading regime (e.g. $10 \%$ strain at $1 \mathrm{~Hz}$ ) which could potentially significant enhance endochondral ossification.
\end{abstract}

Keywords: Bone fracture healing; Mesenchymal stem cells; Chondrogenic growth factors; Osteogenic growth factors; Dynamic loading; Solute transport.

Address correspondence to Smriti Ghimire, Department of Infrastructure Engineering, The University of Melbourne, Melbourne, VIC, 3010, Australia. Electronic mail:

smritig@student.unimelb.edu.au, lihzhang@unimelb.edu.au, s.miramini@unimelb.edu.au, orthovic@gmail.com, pamendis@unimelb.edu.au 


\section{Introduction}

Throughout the bone fracture healing process, tissue production and distribution depend on both the biochemical and biomechanical microenvironments of the fracture site (e.g. concentration of growth factors and interfragmentary movement $)^{10}$. The fundamental understanding of the influence of both chemical and mechanical factors that govern the healing processes is critical for achieving an optimum healing outcome.

During early stage of healing, cells and growth factors diffuse into the fracture site. The interstitial fluid transports nutrients, oxygen and wastes through callus during bone fracture healing. Dynamic loading is one of the physiological processes that induce fluid flow through callus, and fluid flow has been demonstrated to influence cell migration on tumour cells ${ }^{59}$, fibroblasts ${ }^{53}$ and endothelial cells ${ }^{64}$. The enhanced solute transport under cyclic loading has also been supported by experimental studies on articular cartilage ${ }^{8}$ and callus tissue ${ }^{66}$. The role of dynamic loading on solute transport through interstitial fluid in early fracture callus has not been fully understood and studies in this area are limited.

The cellular response in the callus is very sensitive to the mechanical microenvironment ${ }^{41}$. Several mechano-regulation theories ${ }^{55}$, 58 have been proposed and implemented in computational models to numerically predict tissue regeneration in fracture callus ${ }^{15,}$. Assuming that migration, proliferation and differentiation of MSCs, and tissue formation are governed by mechanical stimuli within the callus, these models predicted the sequence and pattern of healing ${ }^{35,42}$. It is known that bone fracture healing is also influenced by biochemical stimuli like growth factors, but their effects on healing were not taken into account in these models.

Bailon-Plaza et al. ${ }^{3}$ proposed a bioregulatory model treating biochemical stimuli as the governing factor for bone fracture healing, which was later extended to incorporate the effects of mechanical stimuli on cartilage and bone formation. Their results demonstrated the importance of mechanical stimuli during early stage of healing through a significant reduction in bone formation when mechanical stimuli were delayed until 6 weeks after fracture ${ }^{4}$. The PDE model was further developed by other researchers, and elaborated to simulate angiogenesis and describe revascularisation, which is a critical healing process during later stages of fracture healing ${ }^{11,23,56}$. However, the effects of dynamic loading on the transport of cells and growth factors were not explicitly investigated in these models.

The combined effects of biochemical and biomechanical stimuli on bone healing, particularly the dynamic loading induced advective (convective) cell and growth factor transport, have not been fully investigated so far. Therefore, the focus of this study is to investigate the effect of dynamic loading on solute transport and tissue differentiation within fracture callus, particularly at early stage of healing. As shown in Fig. 1, the developed model takes into account the biomechanical stimuli mediated stem cell differentiation and tissue production, as well as advective (convective) transport of cells (i.e. MSCs, fibroblasts, chondrocytes and osteoblasts) and growth factors (i.e. osteogenic growth factors and chondrogenic growth factors) induced by interstitial fluid flow as a result of dynamic loading. Osteogenic growth factors (e.g. BMP $-2,-4,-6$, ) and chondrogenic growth factors (e.g. TGF $\beta-2,-3$ ) are two 
important types of growth factors, that regulate the differentiation of MSCs into osteoblasts and chondrocytes, respectively ${ }^{12,13,45,62,69}$. The molecular weight $(25 \mathrm{KDa})$ of these growth factors was adopted from the reported value for TGF $\beta-2$ and BMP $-2^{3,38,44,62}$. Previous studies have suggested that dynamic loading enhances the advective transport of large molecules, like growth factors in biological tissues relative to free diffusion ${ }^{46}$.

\section{Model validation}

The developed model was firstly validated against the experimental data of Harrison et al. ${ }^{29}$. The callus section was divided into three zones (Refer to Fig. 2b), zone 1 or endosteal zone (callus formed inside cortical bone and under bone marrow), zone 2 or cortical zone (callus beneath the cortical bone) and zone 3 or periosteal zone (callus formed outside cortical bone). Fig. 4 shows comparison of numerically predicted tissue distribution pattern of fibrous tissue, cartilage and bone at day 7 with experimental data in endosteal callus (Zone 1), cortical callus (Zone 2), and periosteal callus (Zone 3). It can be seen that the computational results fit the experimental data reasonably well. The model findings are also consistent with the histomorphometric measurements of bone (around 16\%) and cartilage (around 8.3\%) percentage in callus area at day 8 post fracture in diaphyseal fracture of mice tibia ${ }^{22}$. In addition, model predictions are in agreement with the histological study of Vetter et al. ${ }^{63}$ on diaphyseal healing of sheep tibia, which demonstrated a relatively high fibrous tissue content in the cortical and endosteal callus during early reparative phase compared to that in the periosteal callus. The simulation results show that cartilage tissue formation mainly happens in periosteal callus (Fig. 4c), while there is little cartilage and bone formation in cortical callus (Fig. 4b) as cells and growth factors need time to diffuse into this area. This is also supported by experimental findings which show that cartilage tissue formation is mainly on the outer periosteal callus of rat tibia after 8 days post fracture ${ }^{31}$.

\section{Materials and methods}

The theory of porous media has been applied in numerous studies to model biological soft tissues like fracture callus and articular cartilage ${ }^{50,71,75}$. Experimental study of Polacheck et al. ${ }^{59}$ demonstrated that the fluid flow velocity as well as gradient of cell density determines the direction of cell migration. Thus, it is reasonable to model cell migration within a fully saturated porous tissue by using diffusion-advection equation. In present study, fracture callus was treated as a poroelastic material consisting of a solid phase representing various callus tissues (i.e. fibrous tissue, cartilage and bone), an interstitial fluid phase and a solute phase comprising of callus cells (i.e. MSCs, fibroblasts, chondrocytes and osteoblasts) and growth factors (i.e. chondrogenic and osteogenic growth factors). The present study proposes an integrated model which takes into account cell and growth factor transport under dynamic loading, and mechanical stimuli mediated MSC differentiation and tissue production. The developed model could potentially be implemented to identify the loading regimes that produce the optimal healing outcomes.

\section{Transport of cells and growth factors}


The transport equations for cells and growth factors can be obtained based on conservation of mass of the solute in fluid phase ${ }^{72}$.

Mesenchymal stem cells $\left(c^{m}\right)$

$\frac{\partial \bar{c}^{m}}{\partial t}=-\nabla \bullet\left(-D^{m} \nabla \bar{c}^{m}+\mathbf{v}_{\bar{c}}^{m}\right)+S_{p}^{m}-S_{d}^{m}$

where $S_{p}^{m}$ and $S_{d}^{m}$ are the production and degradation rate of MSCs, respectively. $\bar{c}^{m}$ is the medium volume based concentration of MSCs (see Appendix A.1 for detailed expression), $\mathbf{v}^{f}$ is interstitial fluid velocity and $D^{m}$ is the diffusion coefficient of MSCs with consideration of tortuosity factor for the callus matrix. (See Appendix A.2)

As shown in Fig. 1, mechanical loading directly influences MSC differentiation through changing the mechanical microenvironment of MSCs (i.e. stimuli index $S$, refer to Fig. 3). On the other hand, mechanical loading induced interstitial fluid flow in callus enhances the transport of growth factors (i.e. osteogenic growth factor and chondrogenic growth factor) and therefore indirectly enhances chemical stimuli resulting in so called "synergistic effects" (Fig. 1 ), which has been demonstrated in the previous experimental studies ${ }^{30}$. In present study, these synergistic effects have been explicitly incorporated in our computational model.

As MSCs differentiate into fibroblast, chondrocyte and osteoblast in the callus domain, it leads to mass sink of MSCs $\left(S_{d}^{m}\right)$ given by:

$S_{d}^{m}=\left(k_{d}^{f b}+k_{d}^{c}+k_{d}^{b}\right) \bar{c}^{m}+\left(\lambda_{d}^{f b}+\lambda_{d}^{c}+\lambda_{d}^{b}\right) \bar{c}^{m}$

where $k_{d}^{f b}, k_{d}^{c}$ and $k_{d}^{b}$ are the chemical stimuli mediated differentiation rates of MSCs into fibroblast, chondrocyte and osteoblast, respectively (See Appendix A.2). Similarly, $\lambda_{d}^{f b}, \lambda_{d}^{c}$ and $\lambda_{d}^{b}$ are the mechanical stimuli mediated differentiation rates of MSCs into fibroblasts, chondrocytes and osteoblasts, respectively.

The transport equations for fibroblasts $\left(c^{f b}\right)$, chondrocytes $\left(c^{c}\right)$, osteoblasts $\left(c^{b}\right)$, chondrogenic growth factor $\left(g^{c}\right)$ and osteogenic growth factor $\left(g^{b}\right)$ can be expressed similar to that of mesenchymal stem cells. (See appendix A.3).

The differentiation rates of MSCs into fibroblasts, chondrocytes and osteoblasts regulated by local mechanical environment are assumed to be dependent on the magnitude of stimuli index (S) (See Appendix A.4), as follows:

$S_{d}^{m}=\left\{\begin{array}{clll}S_{p m}^{b}=\lambda_{d}^{b} \bar{c} m, & S_{p m}^{c}=S_{p m}^{f b}=0, & \text { for } S<1 & \text { (osteoblasts) } \\ S_{p m}^{c}=\lambda_{d}^{c} \bar{c} m, & S_{p m}^{b}=S_{p m}^{f b}=0, & \text { for } 1<S<3 & \text { (chondrocytes) } \\ S_{p m}^{f b}=\lambda_{d}^{f b} \bar{c} m, & S_{p m}^{b}=S_{p m}^{c}=0, & \text { for } S>3 & \text { (fibroblasts) }\end{array}\right.$

where $S_{p m}^{\alpha}$ is the mechanical stimuli mediated production rate of $\alpha$ cells (Appendix A.3). 
The value of stimuli index $S$ is dependent on octahedral shear strain and fluid velocity (see Appendix A.4). The results of sensitivity analysis indicate that the value of $S$ is much dependent on octahedral shear strain.

\section{Fibrous tissue $\left(m^{f s}\right)$, cartilage $\left(m^{c s}\right)$ and bone $\left(m^{b s}\right)$ production}

The tissue production within the callus which depends on both chemical and mechanical stimuli $^{34,56}$ can be expressed as follows:

$$
\begin{aligned}
& \frac{\partial \bar{m}^{\gamma}}{\partial t}=S_{p}^{\gamma}-S_{d}^{\gamma} \\
& S_{p}^{\gamma}=\left(P_{p c}^{\gamma}+P_{p m}^{\gamma}\right) \bar{c}^{\alpha} \\
& S_{d}^{\gamma}=P_{p c}^{\gamma} k^{\gamma} \bar{m}^{\gamma} \bar{c}^{\alpha}
\end{aligned}
$$

where $\gamma=f s$ (fibrous tissue); $\gamma=c s$ (cartilage tissue); and $\gamma=b s$ (bone tissue). $S_{p}^{\gamma}$ is the production rate of the relevant tissue which is assumed to be the sum of chemical stimuli mediated production rate $\left(P_{p c}^{\gamma}\right)$ and mechanical stimuli mediated production rate $\left(P_{p m}^{\gamma}\right)$ (See Appendix A.5). $S_{d}^{\gamma}$ is the degradation rate of the tissue.

The interstitial fluid motion within the callus is determined from the balance of linear momentum and mass conservation of solid and fluid phases (See Appendix A.6).

\section{Problem Description}

The developed model was implemented to reproduce the experimental observations of Harrison et al. ${ }^{29}$ due to the availability of experimental details (i.e. time dependent healing progression through histological analysis) and then used to investigate the effect of different loading regimes on healing outcomes. A series of computational simulations were carried out to identify the optimal regime that enhances solute transport in fracture callus, stem cell differentiation and tissue formation at early stage of healing. The values of model parameters used this study are given in Table 1 .

\section{Geometry}

Fig. 2a shows a transverse fracture on a mid-section of diaphyseal rat femur. The geometry and size of facture callus adopted in this study were defined based on the experiments of Harrison et al. ${ }^{29}$. The 2D axisymmetric model used in simulation is shown in Fig. 2b. The simplified geometry used by Geris et al. ${ }^{22}$ was adopted to compare our finite element model results. As our model formulation has been implemented in a finite element framework, it can be solved over any complex geometry without limiting to a 2D geometry. All the sharp edges of broken cortex and callus borders have been rounded through a filler of $0.01 \mathrm{~mm}$ radius, to avoid stress concentration regions due to the shape of model geometry. In this study, a series of parametric studies were carried out to investigate the effect of filler radius of the edge of cortex bone on tissue development. Our results show that, while the change of filler radius leads to the change of spatially profile of fibrous tissue near the fracture corner zone, the change of filler radius has little impact on the total content of different tissues in callus. 


\section{Loading Protocol}

As shown in Fig. 2c, it was assumed that the fractured femur was subjected to a dynamic loading representing foot loading patterns (e.g. loading rise time, loading time and recovery time $)^{5,74}$. The loading strains and frequencies in the model were selected based on both previous animal experimental studies ${ }^{2,20,59}$ and physiological relevant loading regime ${ }^{37,49}$.

\section{Assumptions}

To simplify the complicated healing problem, the following assumptions were made in present study:

- The early stage of healing is mainly mediated by the biological actions of $\mathrm{MSCs}^{36}$. At this stage, the majority of MSCs are originated from periosteum, bone marrow and external boundary of callus ${ }^{43}$ and there is little local proliferation of MSCs within the callus.

- The volume fraction of solid phase and fluid phase remains constant during early stage of healing ${ }^{19}$.

- The degradation of cells and growth factors are ignored during early stage of healing.

- There is little change in callus size and geometry during early stage of healing.

- The total cell differentiation rate is the sum of chemical stimuli mediated differentiation rate and mechanical stimuli mediated differentiation rate.

\section{Boundary Conditions}

As shown in Fig. 2b, the following boundary conditions are assumed based on experimental evidences:

- The MSCs $\left(c^{m 0}\right)$ diffuse into fracture callus from periosteum, bone marrow and external boundary of callus ${ }^{31}$.

- The fibroblasts $\left(c^{f b 0}\right)$ diffuse into fracture callus from bone marrow and external boundary of callus ${ }^{60}$ active during the inflammation phase for up to 3 days.

- The chondrogenic growth factors $\left(g^{c 0}\right)$ diffuse into fracture callus from the cambium region of periosteum at the fracture end of the cortex ${ }^{6}$, with a peak around $5-7$ days after fracture ${ }^{13}$.

- The osteogenic growth factors $\left(g^{b 0}\right)$ diffuse into fracture callus from both inner lining of cortex and periosteum ${ }^{6}$; and are active throughout the fracture healing, with a peak around 21 days $^{13}$.

- No flux boundary condition for osteoblasts and chondrocytes at all boundaries, since they are observed to originate from mesenchymal stem cells in the callus ${ }^{60}$. All other cells and growth factors have no flux at the boundaries except mentioned above $\mathrm{e}^{23}$.

\section{Initial conditions}

The initial callus is filled with loose fibrous granulation tissue at early stage of healing ${ }^{48}$. The initial conditions within callus can be assumed as 
Cells:

$\bar{c}^{m}(t=0)=0 ; \bar{c}^{f b}(t=0)=0 ; \bar{c}^{c}(t=0)=0 ; \bar{c}^{b}(t=0)=0$

Growth factors:

$\bar{g}^{c}(t=0)=0 ; \bar{g}^{b}(t=0)=0$

Tissues:

$m^{f s}(t=0)=10 \mathrm{mg} / \mathrm{ml}^{56} ; m^{c s}(t=0)=0 ; m^{b s}(t=0)=0$

\section{Numerical solutions}

The governing equations (1), (A3), (A4), (A6) (See Appendix A) were solved numerically using commercial finite element software package COMSOL Multiphysics ${ }^{\circledR}$ v5.2 ${ }^{17}$. Early fracture callus domain shown in Fig. 2b was modelled using a structured free triangular meshing with 1933 elements. The convergence analysis was performed to determine the mesh size with error of $1 \%$. The time dependent simulation was carried out using the generalised alpha solver with 20745 degree of freedoms for a relative tolerance of $10^{-3}$.

\section{Results}

\section{Free diffusion}

After fracture, the MSCs migrate into fracture callus and differentiate into fibroblasts, osteoblasts and chondrocytes regulated by the growth factor concentration. In order to compare the concentration of these cells and growth factors within different zones of callus as a result of free diffusion and differentiation, their normalised uptake (see Appendix for details) as a function of time in each zone is shown in Fig. 5. The concentration of MSCs $\left(c^{m}\right)$ and fibroblasts $\left(c^{f}\right)$ into callus are normalized to their respective boundary conditions $\left(c^{m 0}\right.$ and $\left.c^{f 0}\right)$; while the concentrations of chondrocytes and osteoblasts are normalised to the boundary conditions of MSCs $\left(c^{m 0}\right)$ as they are differentiated from MSCs. It can be seen from Fig. 5 that the uptake of all cells and growth factors in callus is spatially dependent. The model predicts a relatively high concentration of MSCs, osteogenic and chondrogenic growth factors in the periosteal callus due to the location of their sources at early stage of healing. The significance of chondrogenic and osteogenic growth factors is demonstrated by the relatively high uptake of chondrocytes and osteoblast in periosteal callus compared to other zones (Fig. $5 \mathrm{c}$ and $\mathrm{d}$ ), where there is relatively high concentration of chondrogenic and osteogenic growth factors and MSCs (see Fig. 5a, e and f). Consequently at day 7 post fracture, the model predicted a very low concentration of cartilage in the endosteal callus compared to that in periosteal callus (Fig. 4), which is also consistent with histological observation showing that little cartilage tissue is formed in the endosteal callus during early stage of healing ${ }^{29,63}$.

Sensitivity analyses have been carried out to investigate effect of initial conditions of mesenchymal stem cells $\left(c^{m 0}\right)$, osteogenic growth factor $\left(g^{b 0}\right)$ and chondrogenic growth factor $\left(g^{c 0}\right)$ on tissue formation. The results show that the sensitivity of MSCs and growth factors in 
cartilage formation is spatially dependent, for example, MSCs and chondrogenic growth factor enhances cartilage formation in both endosteal and periosteal callus, whereas the formation of cartilage in cortical cartilage is insensitive to chondrogenic growth factor. On the other hand, MSCs and osteogenic growth factor generally have a positive effect on bone generation across the callus, while chondrogenic growth factor is shown to inhibit the bone formation (Refer to Fig. 9).

\section{Advection (convection)}

To investigate the influence of mechanical loading on cells and growth factors transport, the normalised concentration of MSCs and growth factors under dynamic loading (i.e. advection/ convection) is compared with that under free diffusion (Fig. 6 and Fig. 7). Previous studies of advective (convective) transport of Insulin-like growth factor in cartilage have identified a strain magnitude of $10 \%$ and loading frequency of $1 \mathrm{~Hz}$ as the most effective dynamic loading parameters to enhance solute transport among a range of loading conditions ${ }^{70,71}$. Correspondingly, a cyclic loading (Refer to Fig. 2c) corresponding to $10 \%$ strain at $1 \mathrm{~Hz}$ frequency for 6 hours was adopted in this study.

The temporal as well as spatial effect of dynamic loading on the transport of MSCs is illustrated in Fig. 6. It can be seen from Fig. 6a that, in comparison to free diffusion, dynamic loading leads to a significant increase of MSCs at early stage of loading (e.g. $20 \%$ increase during the first hour of loading) and gradually goes down with the increase of loading time (e.g. down to $10 \%$ increase after 5 hour of loading). The simulation results are consistent with previous studies on dynamic loading induced advective (convective) solute transport in biological tissues (e.g. cartilage) ${ }^{70-72}$. In addition, the enhancement of MSC uptake as a result of dynamic loading could be four times higher in endosteal callus than that in periosteal callus, while dynamic loading has little effect on MSC uptake in cortical callus due to the fact that much less MSCs concentration would have reached this zone over 5 hours. Furthermore, the spatial increase of MSC uptake in Fig. 6b also suggests that the increase in MSC uptake is mainly in boundary zone of the endosteal callus, and the increment gradually moves further into the callus with the increase of loading time.

The effects of dynamic loading on transport of growth factors in different zones of callus are shown in Fig. 7. In comparison to free diffusion, dynamic loading is seen to significantly enhance the uptake of chondrogenic growth factor by around $100 \%$ and $60 \%$ in cortical and periosteal callus, respectively, during the first 5 hour of loading. Among two growth factors, chondrogenic growth factor is predicted to experience a higher percent increase in its concentration compared to that of osteogenic growth factor, due to the fact that the source of chondrogenic growth factor being directly under the loading where there is a relatively higher fluid velocity at fracture gap specifically adjacent to the tip of the bone fragments ${ }^{25}$. On the other hand, the influence of dynamic loading in the uptake of osteogenic growth factor in both endosteal and periosteal callus is limited as the source of osteogenic growth factor is on the periosteal and endosteal layer of cortical bone where the fluid velocity is low. 


\section{Mechanical stimuli mediated cell differentiation and tissue regeneration}

The percent change in fibrous, cartilage and bone tissue concentration under different loading conditions relative to free diffusion is presented in Fig. 8. The inset diagrams show spatial distribution of actual tissue concentration under corresponding loading conditions. The comparison of the results from Fig. 8(a-f) shows that a relatively high loading strain (i.e. 15\%) results in fibrous tissue formation (Fig. 8a), while a relatively low loading strain (i.e. 5\%) or frequency (i.e. $0.01 \mathrm{~Hz}$ ) suppresses the cartilage formation and thereby the endochondral ossification. The model predictions are consistent with the previous computational predictions which showed that low frequencies fail to promote endochondral ossification ${ }^{25}$. Previous experimental studies have also demonstrated that moderate levels of loading (e.g. 10\% strain) improve cell differentiation and accelerate bone healing ${ }^{32}$.

The sensitivity analysis regarding different loading regimes with various strain and frequency combinations (Fig. 8) shows that the change of frequency has little influence on fibrous tissue formation and an increase in frequency by from $1 \mathrm{~Hz}$ to $10 \mathrm{~Hz}$ decreases cartilage formation by around 5\%. In addition, the increase in strain by from $10 \%$ to $15 \%$ increased fibrous and cartilage tissue formation by around $5 \%$ and $15 \%$ relative to control, respectively.

\section{Discussion}

This study investigates the cellular activities including migration, differentiation and tissue formation mediated by both biochemical stimuli (i.e. growth factors) and mechanical stimuli (i.e. strain and fluid velocity) during bone healing. The developed model takes into account the direct contribution of dynamic loading induced mechanical stimuli as well as its indirect contribution through the advective (convective) transport of cells and growth factors within the fracture callus. To our best knowledge, this is the first study that incorporates all the above mentioned healing mechanism into a computational model which could potentially be implemented in identifying optimal loading regimes for better healing outcomes.

The spatio-temporal distributions of MSCs and growth factors across all three regions: periosteal callus, cortical callus and endosteal callus is described from Fig. 5 to Fig. 8. Our simulation results show that tissue formation (Fig. 8 insets) advances progressively from the callus regions where both MSCs and growth factors are abundant. Externally supplied growth factors have also shown to accelerate fracture healing ${ }^{39}$, highlighting the importance of cells and growth factor transport into callus. It is known that dynamic loading generally enhances the transport of solutes through interstitial fluid flow ${ }^{8,70}$. Our simulation results show that the enhanced transport of MSCs and growth factors in the callus due to advection (convection) is more obvious during the first hour of loading. In addition, the increased cell and growth factor concentration under the influence of dynamic loading is spatially dependent due to the spatial profiles of interstitial fluid velocity. Fig. 7 shows that the percent increase of chondrogenic growth factors in the periosteal zone of callus due to dynamic loading is more than 3 -fold than that of osteogenic growth factors because the interstitial fluid velocity in the region near the source of chondrogenic growth factors is much higher than that of osteogenic growth factors ${ }^{25}$ 
(Refer to Fig. 2b). While previous studies have suggested that cell differentiation and tissue distribution pattern ${ }^{43}$ are directly regulated by fluid velocity within the callus, our computational results suggest that interstitial fluid flow in callus also plays an important role in the transport of MSCs and growth factors, and thereby indirectly influences healing outcome. These findings are consistent with previous experimental studies on cell migration ${ }^{59,53}$ and solute transport ${ }^{66,8}$.

In addition, the model predicted a detrimental effect of dynamic loading immediately post fracture (i.e. inhibit the MSC differentiation into chondrocytes and osteoblasts). Our results show that, at Day 1 post-fracture, tissue formation under dynamic loading is less than that under free diffusion without loading. The application of mechanical loading at fracture site immediately after fracture is perceived to inhibit MSC differentiation into chondrocytes and osteoblasts completely ${ }^{4}$ (i.e. both chemical and mechanical differentiation rate, refer to Fig. 3) as high level of mechanical stimuli is unfavourable for a callus tissue ${ }^{18}$ composed of loosely formed granulation tissue, thereby decreasing the tissue concentration of cartilage and bone tissue relative to that under free diffusion. The model predictions are consistent with the experimental observation which showed that mechanical loading may impair cellular response at Day $1^{20,52}$. Early loading of fracture site could also result in cell death and further tissue damage $^{21}$, ultimately a delayed healing ${ }^{67}$. Our simulation results indicate the time of loading has to be carefully chosen to prevent possible negative effects on healing.

It is well known that adequate interfragmentary movement resulting from partial weight bearing exercise during healing encourages endochondral ossification ${ }^{67}$. Our model predicts a significant enhancement in cartilage tissue formation within the callus specifically in the cortical and endosteal regions following the application of dynamic loading (e.g. 10\% strain @ $1 \mathrm{~Hz}$ as shown in Fig. 8b). Although a large strain (e.g. 15\% strain and frequency of $1 \mathrm{~Hz}$ ) could also increase cartilage tissue formation (Fig. 8a), it may lead to excessive fibrous tissue formation specifically in the cortical callus and thereby cause delay fracture gap bridging. The stress concentration in the inner corner of periosteal borders (Refer to Fig. 8a) due to the shape adopted doesn't influence the numerical results ${ }^{24}$. There are numerous evidences demonstrating that formation of cartilage tissue in the fracture gap during the early stage of healing is favourable as it results in indirect fracture healing through endochondral ossification which is a much better healing process compared to direct bone healing ${ }^{48,57}$. Further, the simulation results suggest there could be an optimal loading regime (e.g. 10\% strain @ $1 \mathrm{~Hz}$ as shown in Fig. 8 b) which encourages cartilage tissue formation but inhibits fibrous tissue production at the same time, and thereby enhances endochondral ossification. The loading strains and frequencies in the model used in this study are based on previous experimental studies ${ }^{2,16,26,68}$ with consideration of physiological relevant loading regime ${ }^{37,49}$. For example, Augat et al. ${ }^{1}$ and Bishop et al. $^{7}$ applied a strain of $26 \%$ and $25 \%$ on transverse osteotomy of sheep, respectively. Another experiment by Wolf et al. ${ }^{3}$ involving transverse osteotomy of $3 \mathrm{~mm}$ gap ovine tibial fracture demonstrated that a strain of $16 \%$ enhances the bone healing. In addition, by applying $33 \%$ strain on tibial fracture of sheep Goodship et al. ${ }^{7}$ observed enhanced bridging callus and increased bone stiffness compared to rigid fixation after a healing period of 12 weeks. While there is lack of substantial data on interfragmentary strain in clinical cases ${ }^{40}$, clinical studies on 
tibial fractures showed relatively large interfragmentary movement at initial stage of healing is tolerated $^{14,65}$, and very stiff fixation has been shown to inhibit callus formation and lead to non-unions in clinical cases ${ }^{9}$. Furthermore, in-vitro experiments on mesenchymal stem cells (MSCs) have demonstrated that a strain of $10 \%$ can enhance chondrogenic and osteogenic differentiation $^{37,49}$.

The present study has some limitations. For simplicity and without sacrificing the fundamental healing processes under dynamic loading, a 2-D axisymmetric geometry was adopted in this study. However, if the fracture geometry and loading conditions are too complicated, a comprehensive 3D model should be developed. It mainly focused on the early stage of bone healing (i.e. first week after fracture) during which both the chemical and mechanical conditions are of critical importance for the entire healing process ${ }^{41}$. The boundary conditions adopted in the study are only valid in this stage. In addition, it is assumed that the mechanical properties of callus remain unchanged at this stage. However, as healing progresses (e.g. second week post-fracture), the mechanical properties of fracture callus should be updated in the model with the increase of time. Furthermore, our future study should incorporate angiogenesis which plays a key role in second stage of bone healing. The current model mainly focuses on studying the effects of dynamic loading on advective (convective) transport of cells and growth factors without considering the advective (convective) transport of nutrients, oxygen and wastes in callus.

\section{Conclusion}

In this study, we have developed an experimentally validated computational model to investigate the effect of dynamic loading on the early stage of bone healing. The model is based on porous media theory and incorporates processes such as the advective (convective) transport of cells and growth factors, and mechanical stimuli resulting from tissue deformation and interstitial fluid flow induced by the dynamic loading. The followings are some major findings:

1. During the first week after the fracture, the major component of callus is fibrous tissue and the distribution of various tissues is spatial dependent. For example, the amount of fibrous tissue in cortical zone and periosteal zone is $95 \%$ and $65 \%$, respectively. In addition, the content of cartilage tissue is highest in periosteal zone of callus, which is close to the source of MSCs and chondrogenic growth factors. As for the bone content, it is a similar in periosteal and endosteal zones of callus (i.e. 18\%), whereas there is little bone and cartilage formation in cortical zone.

2. A physiologically relevant dynamic loading could enhance the transport of MSCs further into the endosteal callus (around 20\% during the first hour of loading), but has limited influence in MSC uptake in periosteal and cortical callus. In addition, the dynamic loading enhances the uptake of chondrogenic growth factor uptake by around $100 \%$ and $60 \%$ in cortical and periosteal callus, respectively, but has little effect on the transport of osteogenic growth factor. 
3. An optimal dynamic loading regime (i.e. 10\% strain @ 1Hz) produces the best healing outcomes through encouraging endochondral ossification by enhancing cartilage tissue formation and suppressing fibrous tissue content.

\section{Conflict of Interest}

No benefits in any form have been or will be received from a commercial party related directly or indirectly to the subject of this manuscript. 


\section{References}

1. Andreykiv A., F. van Keulen and P. J. Prendergast. Simulation of fracture healing incorporating mechanoregulation of tissue differentiation and dispersal/proliferation of cells. Biomech Model Mechanobiol 7: 443-461, 2008.

2. Augat P., J. Merk, S. Wolf and L. Claes. Mechanical stimulation by external application of cyclic tensile strains does not effectively enhance bone healing. Journal of orthopaedic trauma 15: 54-60, 2001.

3. Bailon-Plaza A. and M. C. van der Meulen. A mathematical framework to study the effects of growth factor influences on fracture healing. J Theor Biol 212: 191-209, 2001.

4. Bailón-Plaza A. and M. C. H. van der Meulen. Beneficial effects of moderate, early loading and adverse effects of delayed or excessive loading on bone healing. Journal of Biomechanics 36 : 1069-1077, 2003.

5. Barker M. K. and B. B. Seedhom. The relationship of the compressive modulus of articular cartilage with its deformation response to cyclic loading: does cartilage optimize its modulus so as to minimize the strains arising in it due to the prevalent loading regime? Rheumatology (Oxford) 40: 274-284, 2001.

6. Barnes G. L., P. J. Kostenuik, L. C. Gerstenfeld and T. A. Einhorn. Growth Factor Regulation of Fracture Repair. Journal of bone and mineral research 14: 1805-1815, 1999.

7. Bishop N., M. Van Rhijn, I. Tami, R. Corveleijn, E. Schneider and K. Ito. Shear does not necessarily inhibit bone healing. Clinical orthopaedics and related research 443: 307-314, 2006.

8. Bonassar L. J., A. J. Grodzinsky, E. H. Frank, S. G. Davila, N. R. Bhaktav and S. B. Trippel. The effect of dynamic compression on the response of articular cartilage to insulin-like growth factor-I. Journal of Orthopaedic Research 19: 11-17, 2001.

9. Bottlang M., J. Doornink, T. J. Lujan, D. C. Fitzpatrick, J. L. Marsh, P. Augat, B. von Rechenberg, M. Lesser and S. M. Madey. Effects of Construct Stiffness on Healing of Fractures Stabilized with Locking Plates. JBJS 92: 12-22, 2010.

10. Chao E. Y., N. Inoue, J. J. Elias and H. Aro. Enhancement of fracture healing by mechanical and surgical intervention. Clinical orthopaedics and related research 355: S163-S178, 1998.

11. Checa S. and P. J. Prendergast. A mechanobiological model for tissue differentiation that includes angiogenesis: a lattice-based modeling approach. Annals of biomedical engineering 37: 129-145, 2009.

12. Cheng H., W. Jiang, F. M. Phillips, R. C. Haydon, Y. Peng, L. Zhou, H. H. Luu, N. An, B. Breyer, P. Vanichakarn, J. P. Szatkowski, J. Y. Park and T. C. He. Osteogenic activity of the fourteen types of human bone morphogenetic proteins (BMPs). Urologic Oncology: Seminars and Original Investigations 22: 79-80, 2004.

13. Cho T. J., L. C. Gerstenfeld and T. A. Einhorn. Differential temporal expression of members of the transforming growth factor $\beta$ superfamily during murine fracture healing. Journal of bone and mineral research 17: 513-520, 2002.

14. Claes L., R. Grass, T. Schmickal, B. Kisse, C. Eggers, H. Gerngross, W. Mutschler, M. Arand, T. Wintermeyer and A. Wentzensen. Monitoring and healing analysis of 100 tibial shaft fractures. Langenbeck's Archives of Surgery 387: 146-152, 2002.

15. Claes L. E. and C. A. Heigele. Magnitudes of local stress and strain along bony surfaces predict the course and type of fracture healing. Journal of Biomechanics 32: 255-266, 1999.

16. Claes L. E., C. A. Heigele, C. Neidlinger-Wilke, D. Kaspar, W. Seidl, K. J. Margevicius and P. Augat. Effects of mechanical factors on the fracture healing process. Clinical orthopaedics and related research 355: S132-S147, 1998.

17. COMSOL. Multiphysics ${ }^{\circledR}$ v. 5.2. COMSOL AB, Stockholm, Sweden.

18. Garcia-Aznar J. M., J. H. Kuiper, M. J. Gomez-Benito, M. Doblare and J. B. Richardson. Computational simulation of fracture healing: influence of interfragmentary movement on the callus growth. J Biomech 40: 1467-1476, 2007. 
19. Gardiner B., D. Smith, P. Pivonka, A. Grodzinsky, E. Frank and L. Zhang. Solute transport in cartilage undergoing cyclic deformation. Computer methods in biomechanics and biomedical engineering 10: 265-278, 2007.

20. Gardner M. J., M. C. van der Meulen, D. Demetrakopoulos, T. M. Wright, E. R. Myers and M. P. Bostrom. In vivo cyclic axial compression affects bone healing in the mouse tibia. Journal of Orthopaedic Research 24: 1679-1686, 2006.

21. Gardnera T. N., T. Stoll, L. Marks, S. Mishra and M. Knothe Tate. The influence of mechanical stimulus on the pattern of tissue differentiation in a long bone fracture - an FEM study. Journal of Biomechanics 33: 415-425, 2000.

22. Geris L., A. Gerisch, C. Maes, G. Carmeliet, R. Weiner, J. Vander Sloten and H. Van Oosterwyck. Mathematical modeling of fracture healing in mice: comparison between experimental data and numerical simulation results. Medical and Biological Engineering and Computing 44: 280-289, 2006.

23. Geris L., A. Gerisch, J. V. Sloten, R. Weiner and H. V. Oosterwyck. Angiogenesis in bone fracture healing: a bioregulatory model. Journal of Theoretical Biology 251: 137-158, 2008.

24. Geris L., J. Vander Sloten and H. Van Oosterwyck. Connecting biology and mechanics in fracture healing: an integrated mathematical modeling framework for the study of nonunions. Biomechanics and modeling in mechanobiology 9: 713-724, 2010.

25. González-Torres L., M. Gómez-Benito, M. Doblaré and J. García-Aznar. Influence of the frequency of the external mechanical stimulus on bone healing: a computational study. Medical engineering \& physics 32: 363-371, 2010.

26. Goodship A. and J. Kenwright. The influence of induced micromovement upon the healing of experimental tibial fractures. Bone \& Joint Journal 67: 650-655, 1985.

27. Guérin G., D. Ambard and P. Swider. Cells, growth factors and bioactive surface properties in a mechanobiological model of implant healing. Journal of Biomechanics 42: 2555-2561, 2009.

28. Han L., A. J. Grodzinsky and C. Ortiz. Nanomechanics of the Cartilage Extracellular Matrix. Annu Rev Mater Res 41: 133-168, 2011.

29. Harrison L. J., J. L. Cunningham, L. Strömberg and A. E. Goodship. Controlled induction of a pseudoarthrosis_a study using a rodent model. Journal of orthopaedic trauma 17: 11-21, 2003.

30. Helm C.-L., M. Fleury, A. Zisch, F. Boschetti and M. Swartz. Synergy between interstitial flow and VEGF directs capillary morphogenesis in vitro through a gradient amplification mechanism. Proceedings of the National Academy of Sciences of the United States of America 102: 1577915784, 2005.

31. Henricson A., A. Hulth and O. Johnell. The cartilaginous fracture callus in rats. Acta Orthopaedica Scandinavica 58: 244-248, 1987.

32. Hou T., Q. Li, F. Luo, J. Xu, Z. Xie, X. Wu and C. Zhu. Controlled dynamization to enhance reconstruction capacity of tissue-engineered bone in healing critically sized bone defects: an in vivo study in goats. Tissue Engineering Part A 16: 201-212, 2009.

33. Huiskes R., W. Van Driel, P. Prendergast and K. Søballe. A biomechanical regulatory model for periprosthetic fibrous-tissue differentiation. Journal of materials science: Materials in medicine 8: 785-788, 1997.

34. Isaksson H., C. C. van Donkelaar, R. Huiskes and K. Ito. A mechano-regulatory bone-healing model incorporating cell-phenotype specific activity. J Theor Biol 252: 230-246, 2008.

35. Isaksson H., W. Wilson, C. C. van Donkelaar, R. Huiskes and K. Ito. Comparison of biophysical stimuli for mechano-regulation of tissue differentiation during fracture healing. Journal of Biomechanics 39: 1507-1516, 2006.

36. Ito H. Chemokines in mesenchymal stem cell therapy for bone repair: a novel concept of recruiting mesenchymal stem cells and the possible cell sources. Modern rheumatology 21: 113121, 2011. 
37. Jagodzinski M., A. Breitbart, M. Wehmeier, E. Hesse, C. Haasper, C. Krettek, J. Zeichen and S. Hankemeier. Influence of perfusion and cyclic compression on proliferation and differentiation of bone marrow stromal cells in 3-dimensional culture. Journal of Biomechanics 41: 1885-1891, 2008. 38. Joyce M., R. Terek, S. Jingushi and M. Bolander. Role of Transforming Growth Factor- $\beta$ in Fracture Repair. Annals of the New York Academy of Sciences 593: 107-123, 1990.

39. Joyce M. E., A. B. Roberts, M. B. Sporn and M. E. Bolander. Transforming growth factorbeta and the initiation of chondrogenesis and osteogenesis in the rat femur. The Journal of cell biology 110: 2195-2207, 1990.

40. Kenwright J., J. Richardson, J. Cunningham, S. White, A. Goodship, M. Adams, P. Magnussen and J. Newman. Axial movement and tibial fractures. A controlled randomised trial of treatment. Bone \& Joint Journal 73: 654-659, 1991.

41. Klein P., H. Schell, F. Streitparth, M. Heller, J. P. Kassi, F. Kandziora, H. Bragulla, N. P. Haas and G. N. Duda. The initial phase of fracture healing is specifically sensitive to mechanical conditions. Journal of Orthopaedic Research 21: 662-669, 2003.

42. Lacroix D. and P. Prendergast. A mechano-regulation model for tissue differentiation during fracture healing: analysis of gap size and loading. Journal of Biomechanics 35: 1163-1171, 2002.

43. Lacroix D., P. J. Prendergast, G. Li and D. Marsh. Biomechanical model to simulate tissue differentiation and bone regeneration: application to fracture healing. Med Biol Eng Comput 40: 14-21, 2002.

44. Lauzon M.-A., É. Bergeron, B. Marcos and N. Faucheux. Bone repair: new developments in growth factor delivery systems and their mathematical modeling. Journal of controlled release 162: 502-520, 2012.

45. Marsell R. and T. A. Einhorn. The role of endogenous bone morphogenetic proteins in normal skeletal repair. Injury 40: S4-S7, 2009.

46. Mauck R. L., C. T. Hung and G. A. Ateshian. Modeling of Neutral Solute Transport in a Dynamically Loaded Porous Permeable Gel: Implications for Articular Cartilage Biosynthesis and Tissue Engineering. Journal of Biomechanical Engineering 125: 602-614, 2003.

47. McCartney W., B. J. M. Donald and M. S. J. Hashmi. Comparative performance of a flexible fixation implant to a rigid implant in static and repetitive incremental loading. Journal of materials processing technology 169: 476-484, 2005.

48. McKibbin B. The biology of fracture healing in long bones. J Bone Joint Surg Br 60-B: 150$162,1978$.

49. McMahon L. A., A. J. Reid, V. A. Campbell and P. J. Prendergast. Regulatory effects of mechanical strain on the chondrogenic differentiation of MSCs in a collagen-GAG scaffold: experimental and computational analysis. Annals of biomedical engineering 36: 185-194, 2008.

50. Miramini S., L. Zhang, M. Richardson, P. Mendis and P. Ebeling. Influence of fracture geometry on bone healing under locking plate fixations: A comparison between oblique and transverse tibial fractures. Medical engineering \& physics 38: 1100-1108, 2016.

51. Miramini S., L. Zhang, M. Richardson, P. Mendis, A. Oloyede and P. Ebeling. The relationship between interfragmentary movement and cell differentiation in early fracture healing under locking plate fixation. Australas Phys Eng Sci Med 39: 123-133, 2016.

52. Moalli M., N. Caldwell, P. Patil and S. Goldstein. An In Vivo Model for Investigations of Mechanical Signal Transduction in Trabecular Bone. Journal of bone and mineral research 15: 13461353, 2000.

53. Ng C. and M. Swartz. Fibroblast alignment under interstitial fluid flow using a novel 3-D tissue culture model. American journal of physiology. Heart and circulatory physiology 284: H1771H1777, 2003.

54. Olsen L., J. A. Sherratt and P. K. Maini. A mechanochemical model for adult dermal wound contraction: on the permanence of the contracted tissue displacement profile. Journal of Theoretical Biology 177: 113-128, 1995. 
55. Pauwels F. [A new theory on the influence of mechanical stimuli on the differentiation of supporting tissue. The tenth contribution to the functional anatomy and causal morphology of the supporting structure]. Z Anat Entwicklungsgesch 121: 478-515, 1960.

56. Peiffer V., A. Gerisch, D. Vandepitte, H. V. Oosterwyck and L. Geris. A hybrid bioregulatory model of angiogenesis during bone fracture healing. Biomech Model Mechanobiol 10: 383-395, 2011.

57. Perren S. M. Evolution of the internal fixation of long bone fractures. The scientific basis of biological internal fixation: choosing a new balance between stability and biology. Journal of Bone and Joint Surgery (British Volume) 84: 1093-1110, 2002.

58. Perren S. M. Physical and biological aspects of fracture healing with special reference to internal fixation. Clinical Orthopaedics \& Related Research 138: 175-196, 1979.

59. Polacheck W., J. Charest and R. Kamm. Interstitial flow influences direction of tumor cell migration through competing mechanisms. Proceedings of the National Academy of Sciences of the United States of America 108: 11115-11120, 2011.

60. Postacchini F., S. Gumina, D. Perugia and C. De Martino. Early Fracture Callus in the Diaphysis of Human Long Bones: Histologic and Ultrastructural Study. Clinical orthopaedics and related research 218-228, 1995.

61. Prendergast P. J., R. Huiskes and K. Søballe. Biophysical stimuli on cells during tissue differentiation at implant interfaces. Journal of Biomechanics 30: 539-548, 1997.

62. Solheim E. Growth factors in bone. Int Orthop 22: 410-416, 1998.

63. Vetter A., D. R. Epari, R. Seidel, H. Schell, P. Fratzl, G. N. Duda and R. Weinkamer. Temporal tissue patterns in bone healing of sheep. Journal of Orthopaedic Research 28: 1440-1447, 2010.

64. Vickerman V., J. Blundo, S. Chung and R. Kamm. Design, fabrication and implementation of a novel multi-parameter control microfluidic platform for three-dimensional cell culture and realtime imaging. Lab on a chip 8: 1468, 2008.

65. Wehner T., L. Claes, F. Niemeyer, D. Nolte and U. Simon. Influence of the fixation stability on the healing time-a numerical study of a patient-specific fracture healing process. Clinical biomechanics 25: 606-612, 2010.

66. Witt F., G. N. Duda, C. Bergmann and A. Petersen. Cyclic mechanical loading enables solute transport and oxygen supply in bone healing: an in vitro investigation. Tissue Engineering Part A 20: 486-493, 2014.

67. Wolf J., A. White, M. Panjabi and W. Southwick. Comparison of cyclic loading versus constant compression in the treatment of long-bone fractures in rabbits. J Bone Joint Surg Am 63: 805-810, 1981.

68. Wolf S., A. Janousek, J. Pfeil, W. Veith, F. Haas, G. Duda and L. Claes. The effects of external mechanical stimulation on the healing of diaphyseal osteotomies fixed by flexible external fixation. Clinical biomechanics 13: 359-364, 1998.

69. Yamaguchi A. Regulation of differentiation pathway of skeletal mesenchymal cells in cell lines by transforming growth factor- $\beta$ superfamily. In: Seminars in cell biologyElsevier, 1995, p. 165173.

70. Zhang L. Solute transport in cyclic deformed heterogeneous articular cartilage. International Journal of Applied Mechanics 3: 507-524, 2011.

71. Zhang L., B. S. Gardiner, D. W. Smith, P. Pivonka and A. Grodzinsky. The effect of cyclic deformation and solute binding on solute transport in cartilage. Arch Biochem Biophys 457: 47-56, 2007.

72. Zhang L., B. S. Gardiner, D. W. Smith, P. Pivonka and A. Grodzinsky. A fully coupled poroelastic reactive-transport model of cartilage. Molecular and Cellular Biomechanics 5: 133, 2008.

73. Zhang L., B. S. Gardiner, D. W. Smith, P. Pivonka and A. J. Grodzinsky. Integrated model of IGF-I mediated biosynthesis in a deformed articular cartilage. Journal of Engineering Mechanics 135: 439-449, 2009. 
74. Zhang L., S. Miramini, D. W. Smith, B. S. Gardiner and A. J. Grodzinsky. Time evolution of deformation in a human cartilage under cyclic loading. Ann Biomed Eng 43: 1166-1177, 2015.

75. Zhang L., M. Richardson and P. Mendis. Role of chemical and mechanical stimuli in mediating bone fracture healing. Clinical and Experimental Pharmacology and Physiology 39: 706710, 2012. 


\begin{tabular}{|c|c|}
\hline Parameters & Expression \\
\hline Coefficient of stem cell diffusion $\left(D^{h m}\right)$ & $0.1715 \mathrm{~mm}^{2} / \mathrm{day}^{56}$ \\
\hline Coefficient of stem cell diffusion $\left(\boldsymbol{K}^{h \boldsymbol{h}}\right)$ & $0.025 \mathrm{~g} / \mathrm{ml}^{56}$ \\
\hline Diffusion coefficient of fibroblast $\left(D^{f b}\right)$ & $0.245 \mathrm{~mm}^{2} / \mathrm{day}^{56}$ \\
\hline Diffusion coefficient of osteogenic growth factor $\left(D^{g b}\right)$ & $0.06125 \mathrm{~mm}^{2} / \mathrm{day}^{56}$ \\
\hline Diffusion coefficient of chondrogenic growth gactor $\left(D^{g c}\right)$ & $0.06125 \mathrm{~mm}^{2} / \mathrm{day}^{56}$ \\
\hline $\begin{array}{l}\text { Differentiation of stem cells into fibroblasts due to chemical stimuli } \\
\left(\boldsymbol{k}_{\boldsymbol{d}}^{f \boldsymbol{b}}\right)\end{array}$ & $0.01 /$ day $^{56}$ \\
\hline $\begin{array}{l}\text { Differentiation of stem cells into fibroblasts due to mechanical } \\
\text { stimuli }\left(\lambda_{d}^{f b}\right)\end{array}$ & $0.01 /$ day $^{1}$ \\
\hline $\begin{array}{l}\text { Coefficient of chondrocyte differentiation due to chemical stimuli } \\
\left(\boldsymbol{Y}_{2}\right)\end{array}$ & $40 /$ day $^{3}$ \\
\hline $\begin{array}{l}\text { Coefficient of chondrocyte differentiation due to chemical stimuli } \\
\left(\boldsymbol{H}_{2}\right)\end{array}$ & $10 \mathrm{ng} / \mathrm{ml}^{56}$ \\
\hline $\begin{array}{l}\text { Differentiation of stem cells into chondrocytes due to mechanical } \\
\text { stimuli }\left(\lambda_{\boldsymbol{d}}^{c}\right)\end{array}$ & $0.3 /$ day $^{1}$ \\
\hline $\begin{array}{l}\text { Coefficient of osteoblast differentiation due to chemical stimuli } \\
\left(\boldsymbol{Y}_{\mathbf{1}}\right)\end{array}$ & $3 /$ day $^{3}$ \\
\hline $\begin{array}{l}\text { Coefficient of osteoblast differentiation due to chemical stimuli } \\
\left(\boldsymbol{H}_{\mathbf{1}}\right)\end{array}$ & $10 \mathrm{ng} / \mathrm{ml}^{56}$ \\
\hline $\begin{array}{l}\text { Differentiation of stem cells into osteoblasts due to mechanical } \\
\text { stimuli }\left(\boldsymbol{\lambda}_{\boldsymbol{d}}^{\boldsymbol{b}}\right)\end{array}$ & $(0.005+0.145 x S) /$ day $^{1}$ \\
\hline Synthesis of fibrous tissue due to chemical stimuli $\left(\boldsymbol{P}_{\boldsymbol{p c}}^{\boldsymbol{f} \boldsymbol{s}}\right)$ & $0.2 / \mathrm{day}^{56}$ \\
\hline Synthesis of fibrous tissue due to mechanical stimuli $\left(\lambda_{p}^{f s}\right)$ & $0.06 /$ day $^{1}$ \\
\hline Synthesis of cartilage due to chemical stimuli $\left(\boldsymbol{P}_{\boldsymbol{p c}}^{\boldsymbol{c} \boldsymbol{S}}\right)$ & $0.2 / \mathrm{day}^{56}$ \\
\hline Synthesis of cartilage due to mechanical stimuli $\left(\lambda_{p}^{c s}\right)$ & $0.2 /$ day $^{1}$ \\
\hline Synthesis of bone due to chemical stimuli $\left(\boldsymbol{P}_{\boldsymbol{p c}}^{\boldsymbol{b} \boldsymbol{s}}\right)$ & $2 /$ day $^{56}$ \\
\hline Synthesis of bone due to mechanical stimuli $\left(\lambda_{p}^{b s}\right)$ & $0.05 /$ day $^{1}$ \\
\hline Degradation of fibrous tissue $\left(\boldsymbol{k}^{f s}\right)$ & $10 \mathrm{~g} / \mathrm{ml}^{56}$ \\
\hline Degradation of cartilage $\left(\boldsymbol{k}^{c \boldsymbol{s}}\right)$ & $10 \mathrm{~g} / \mathrm{ml}^{56}$ \\
\hline Degradation of bone $\left(\boldsymbol{k}^{\boldsymbol{b s}}\right)$ & $10 \mathrm{~g} / \mathrm{ml}^{56}$ \\
\hline Boundary condition of stem cells $\left(\boldsymbol{c}^{\mathbf{m 0}}\right)$ & $\begin{array}{l}1.6 \times 10^{4} \text { cells } / \mathrm{ml}^{*} \text { (first } 7 \\
\text { days after fracture) }{ }^{56}\end{array}$ \\
\hline Boundary condition of fibroblasts $\left(\boldsymbol{c}^{\boldsymbol{f b \mathbf { 0 }}}\right)$ & $\begin{array}{l}2 \times 10^{4} \text { cells } / \mathrm{ml}(\text { first } 3 \\
\text { days after fracture) }\end{array}$ \\
\hline Boundary condition of chondrogenic growth factor $\left(\boldsymbol{g}^{\boldsymbol{c 0}}\right)$ & $\begin{array}{l}2 \mu \mathrm{g} / \mathrm{ml} \text { (first } 5 \text { days after } \\
\text { fracture) }\end{array}$ \\
\hline Boundary condition of osteogenic growth factor $\left(\boldsymbol{g}^{\boldsymbol{b} \mathbf{0}}\right)$ & $\begin{array}{l}2 \mu \mathrm{g} / \mathrm{ml} \text { (first } 10 \text { days after } \\
\text { fracture) }\end{array}$ \\
\hline Young's Modulus of callus & $0.05(\mathrm{MPa})^{47}$ \\
\hline Young's Modulus of cortical bone & $20000(\mathrm{MPa})^{42}$ \\
\hline Poisson's ratio of callus & $0.1^{42}$ \\
\hline Poisson's ratio of cortical bone & $0.3^{42}$ \\
\hline Permeability of cortical bone & $10^{-17}\left(\mathrm{~m}^{4} / \mathrm{Ns}\right)^{42}$ \\
\hline Permeability of callus & $10^{-14}\left(\mathrm{~m}^{4} / \mathrm{Ns}\right)^{42}$ \\
\hline Fluid compression modulus of callus & $2300(\mathrm{MPa})^{42}$ \\
\hline
\end{tabular}




\begin{tabular}{|l|l|}
\hline Fluid compression modulus of cortical bone & $2300(\mathrm{MPa})^{42}$ \\
\hline Solid compression modulus of callus & $2300(\mathrm{MPa})^{42}$ \\
\hline Solid compression modulus of cortical bone & $13920(\mathrm{MPa})^{42}$ \\
\hline
\end{tabular}

Table 1 Parameters used throughout this study. The typical values for time (1 day), length $(3.5 \mathrm{~mm})$, cell density $\left(10^{6}\right.$ cells $\left./ \mathrm{ml}\right)$, tissue $(0.1 \mathrm{~g} / \mathrm{ml})$ and growth factor concentration $(100 \mathrm{ng} / \mathrm{ml})$ used to non-dimensionalise above coefficients are adapted from Peiffer et al. $(2011)^{56}$. For computational purpose, molecular weight of cartilage $(0.4 \mathrm{MDa})^{28}$ and growth factors $(25 \mathrm{KDa})^{39}$ resulted in the parameter values of Table 1. *Adjusted to account for the added boundary of MSCs at periosteum. 


\section{List of Figures}

Fig. 1 A schematic overview of the model proposed in this study

Fig. 2 (a) Schematic diagram of coronal section of a fractured femur; (b) Fracture callus domain of rodent femur, with dimensions adopted from Geris et al. ${ }^{23} \cdot c^{m 0}, c^{f b 0}, g^{c 0}$ and $g^{b 0}$ are the boundary conditions of MSCs $\left(c^{m}\right)$, fibroblasts $\left(c^{f b}\right)$, chondrogenic growth factor $\left(g^{c}\right)$, and osteogenic growth factor $\left(g^{b}\right)$ respectively. The inset diagram $\boldsymbol{A}$ shows rounded corner geometry adopted along broken edges of cortex and callus borders with a filler of radius $(R) 0.01 \mathrm{~mm}$; and $(\boldsymbol{c})$ Loading protocol used in this study ${ }^{5,74}$. Each loading cycle consists of loading phase $\left(t_{L}\right)$ and recovery phase $\left(t_{R}\right)$ (i.e. time period $T=t_{L}+t_{R}$ ) and a peak load $(F)$

Fig. 3 Representative cell differentiation rate due to chemical stimuli and mechanical stimuli based on mechanical stimuli index $(S)^{1,51}$. This is based on the concept that if the level of mechanical stimuli is unfavourable, the differentiation rate of MSCs into that cell type is completely inhibited ${ }^{4}$

Fig. 4 Comparison of model prediction of callus tissue differentiation with experimental results of Harrison, Cunningham, Strömberg and Goodship 29. (a) Endosteal callus; (b) Cortical callus; and (c) Periosteal callus

Fig. 5 Normalised time dependent cell uptake in fracture callus under free diffusion across different callus regions (a) MSCs $\left(c^{m}\right)$; (b) Fibroblasts $\left(c^{f b}\right) ;(\boldsymbol{c})$ Chondrocytes $\left(c^{c}\right)$; (d) Osteoblasts $\left(c^{b}\right)$; (e) Osteogenic growth factor $\left(g^{b}\right)$; and $(f)$ Chondrogenic growth factor $\left(g^{c}\right)$. MSCs and fibroblasts are normalised to their boundary values (i.e. $c^{m 0}$ and $c^{f b 0}$ ) respectively, while chondrocytes and osteoblasts are normalised to the boundary conditions of stem cells (i.e. $\left.c^{m 0}\right)$. Growth factors $g^{b}$ and $g^{c}$ are normalised to their boundary conditions (i.e. $g^{b 0}$ and $\left.g^{c 0}\right)$, respectively.

Fig. 6 Percent increase in normalised mesenchymal stem cell concentration under dynamic loading in comparison to free diffusion. (a) Time dependent stem cell concentration; and (b) spatial dependent stem cell concentration at Section $X-X$

Fig. 7 Percent increase in normalised growth factor concentration under dynamic loading in comparison to free diffusion across different callus regions. (a) Osteogenic growth factor $\left(g^{b}\right)$; and (b) Chondrogenic growth factor $\left(g^{c}\right)$

Fig. 8 Percent change in fibrous tissue, cartilage and bone concentration in callus under different loading conditions relative to control (i.e. free diffusion). Each inset diagram shows spatial distribution of actual tissue concentration under corresponding loading conditions.

Fig. 9 Sensitivity analyses of the initial boundary conditions of mesenchymal stem cells $\left(c^{m 0}\right)$, osteogenic growth factor $\left(g^{b 0}\right)$ and chondrogenic growth factor $\left(g^{c 0}\right)$ on tissue formation. 
Appendix A

\section{Volume fraction of solid, fluid and solute}

The volume fraction of solid, fluid and solute phase of the porous callus domain can be represented by $\phi^{s}, \phi^{f}$ and $\phi^{w}$, respectively. As the volume of cells, growth factors and other nutrients are ignorable at tissue level compared to the volume of solid and fluid phase of the callus ${ }^{27}$, we obtain:

$\phi^{f}+\phi^{s} \cong 1$

The relationship between the medium volume based solute concentration $\left(\bar{c}^{w}\right)$ and solvent volume based solute concentration $\left(c^{w}\right)$ can be expressed as:

$\bar{c}^{w}=\phi^{f} c^{w}$

Similarly, the medium volume based tissue concentration $\left(\bar{c}^{s}\right)$ can be expressed as:

$\bar{c}^{s}=\left(1-\phi^{f}\right) c^{s}$

where $c^{S}$ is solvent volume based tissue concentration.

\section{MSC diffusion and differentiation}

The diffusion coefficient of MSCs for the callus matrix ${ }^{23}$ as follows:

$D^{m}=\frac{D^{h m} m}{\left(K^{h m}\right)^{2}+m^{2}}$

where $D^{h m}$ and $K^{h m}$ are coefficients of cell migration depending on the total matrix density $(m)$ of the callus.

The chemical stimuli mediated differentiation rates of MSCs into chondrocyte $\left(k_{d}^{c}\right)$ and osteoblast $\left(k_{d}^{b}\right)$ can be expressed by using Hill function ${ }^{3}$ as follows:

$k_{d}^{b}=\frac{Y_{1} g^{b}}{H_{1}+g^{b}}$

$k_{d}^{c}=\frac{Y_{2} g^{c}}{H_{2}+g^{c}}$

Where $H_{1}, H_{2}, Y_{1}$ and $Y_{2}$ are parameters representing growth factor mediated MSC differentiation. $k_{d}^{f b}$ is assumed to be constant ${ }^{54}$.

\section{Transport equation for cells and growth factors}

The transport equations of fibroblasts $\left(c^{f b}\right)$, chondrocytes $\left(c^{c}\right)$, osteoblasts $\left(c^{b}\right)$ can be expressed as: 


$$
\begin{aligned}
& \frac{\partial \bar{c}^{\alpha}}{\partial t}=-\nabla \bullet\left(-D^{\alpha} \nabla \bar{c}^{\alpha}+\mathbf{v}^{f} \bar{c}^{\alpha}\right)+S_{p}^{\alpha}-S_{d}^{\alpha} \\
& S_{p}^{\alpha}=\left(k_{d}^{\alpha}+\lambda_{d}^{\alpha}\right) c^{m}
\end{aligned}
$$

where, $\alpha=f b$ (fibroblasts), $\alpha=c$ (chondrocytes) and $\alpha=b$ (osteoblasts). $S_{p}^{\alpha}$ is the production rate of $\alpha$ cells which is assumed to be the sum of chemical stimuli mediated production rate $\left(k_{d}^{\alpha}\right)$ and mechanical stimuli mediated production rate $\left(\lambda_{d}^{\alpha}\right) . S_{d}^{\alpha}$ is the degradation rate of $\alpha$ cells and $D^{\alpha}$ is the diffusion coefficient of $\alpha$ cells in fracture callus.

Chondrogenic growth factors $\left(g^{c}\right)$ and osteogenic growth factors $\left(g^{b}\right)$

The mass balance equation for chondrogenic $\left(g^{c}\right)$ and osteogenic growth factor $\left(g^{b}\right)$ is given by

$\frac{\partial \bar{g}^{\beta}}{\partial t}=-\nabla \bullet\left(-D^{\beta} \nabla \bar{g}^{\beta}+\mathbf{v}^{f} \bar{g}^{\beta}\right)+S_{p}^{\beta}-S_{d}^{\beta}$

where $\beta=c$ (chondrogenic growth factors) and $\beta=b$ (osteogenic growth factors). $S_{p}^{\beta}$ and $S_{d}^{\beta}$ are the production rate and degradation rate of growth factors, respectively. $D^{\beta}$ is the diffusion coefficient of the growth factors in fracture callus.

\section{Stimuli Index (S)}

Stimuli Index $S$ is obtained from interstitial fluid phase velocity $\left(\mathbf{v}^{f}\right)$ and octahedral shear strain $(\tau)$ within the callus ${ }^{33}$.

$S=\frac{\tau}{0.0375}+\frac{\mathbf{v}^{f}}{3 \times 10^{-6}(\mathrm{~m} / \mathrm{s})}$

It is assumed that, during early stage of healing, low magnitude of stimuli index $(S<1)$ results in differentiation of osteoblast, moderate magnitude of stimuli index $(1<S<3)$ favours differentiation of chondrocytes while high magnitude of stimuli index $(S<1)$ leads to fibroblast differentiation ${ }^{51}$.

\section{Production of tissues due to mechanical stimuli}

Similar to the cell differentiation pattern shown in Fig. 3, the production rate of fibrous tissue, cartilage and bone due to mechanical stimuli also depends on dynamic loading as follows:

$P_{p m}^{\gamma}=\left\{\begin{array}{clll}P_{p m}^{b s}=\lambda_{p}^{b s} \bar{c}^{b}, & P_{p m}^{c s}=P_{p m}^{f s}=0, & \text { for } S<1 \quad \text { (bone formation) } \\ P_{p m}^{c s}=\lambda_{p}^{c s} \bar{c}^{c}, & P_{p m}^{b s}=P_{p m}^{f s}=0, & \text { for } 1<S<3 \quad \text { (cartilage formation) } \\ P_{p m}^{f s}=\lambda_{p}^{f s} \bar{c} f b, & P_{p m}^{b s}=P_{p m}^{c s}=0, & \text { for } S>3 \quad \text { (fibrous tissue formation) }\end{array}\right.$

\section{Balance of linear momentum}


Assuming callus as homogeneous, isotropic and linear elastic mixture having no body and inertial forces, for an infinitesimal strain, the balance of linear momentum can be expressed as ${ }^{73}$ :

$-\nabla p+\left(\lambda_{s}+2 \mu_{s}\right) \nabla\left(\nabla \bullet \mathbf{u}^{s}\right)+\mu_{s} \nabla^{2} \mathbf{u}^{s}=0$

where $p$ is the interstitial fluid pressure; $\lambda_{\mathrm{s}}$ and $\mu_{\mathrm{s}}$ are Lame's constants; and $\mathbf{u}^{s}$ is the solid phase displacement vector.

Conservation of mass of solid and fluid phases

From the mass balance equation for solid and fluid phase and Darcy's law, the interstitial fluid motion within the callus ${ }^{71,74}$ can be expressed as

$\nabla \bullet\left(\mathbf{v}^{\boldsymbol{s}}-\boldsymbol{k} \nabla p\right)=0$

where $\mathbf{v}^{\boldsymbol{s}}$ is the solid phase velocity, $\boldsymbol{k}$ is the hydraulic permeability tensor and $p$ is the interstitial fluid pressure.

\section{Cell and growth factor uptake ratio}

The average normalised uptake ratio for cells and growth factors in each zone is computed as follows ${ }^{70}$ :

$\bar{c}_{a v g}^{w}=\frac{\int_{0}^{V_{0}} \bar{c}^{w} d V}{c_{0}^{w} V_{0}}$

$\bar{g}_{a v g}^{w}=\frac{\int_{0}^{V_{0}} \bar{g}^{w} d V}{g_{0}^{w} V_{0}}$

where $c^{w}=c^{m}, c^{f b}, c^{c}$ and $c^{b}$ for MSCs, fibroblasts, chondrocytes and osteoblasts concentration, $g^{w}=g^{b}$ and $g^{c}$ for osteogenic and chondrogenic growth factor concentration, respectively. $c_{0}^{W}$ is the saturated concentration of particular cell over callus volume $V_{0}$. The uptake of osteogenic and chondrogenic growth factors are normalised to their respective boundary conditions $\left(g_{0}^{w}=g^{b 0}\right.$ and $\left.g^{c 0}\right)$. 
Advective transport \& Mechanical stimuli (Mechanical loading)

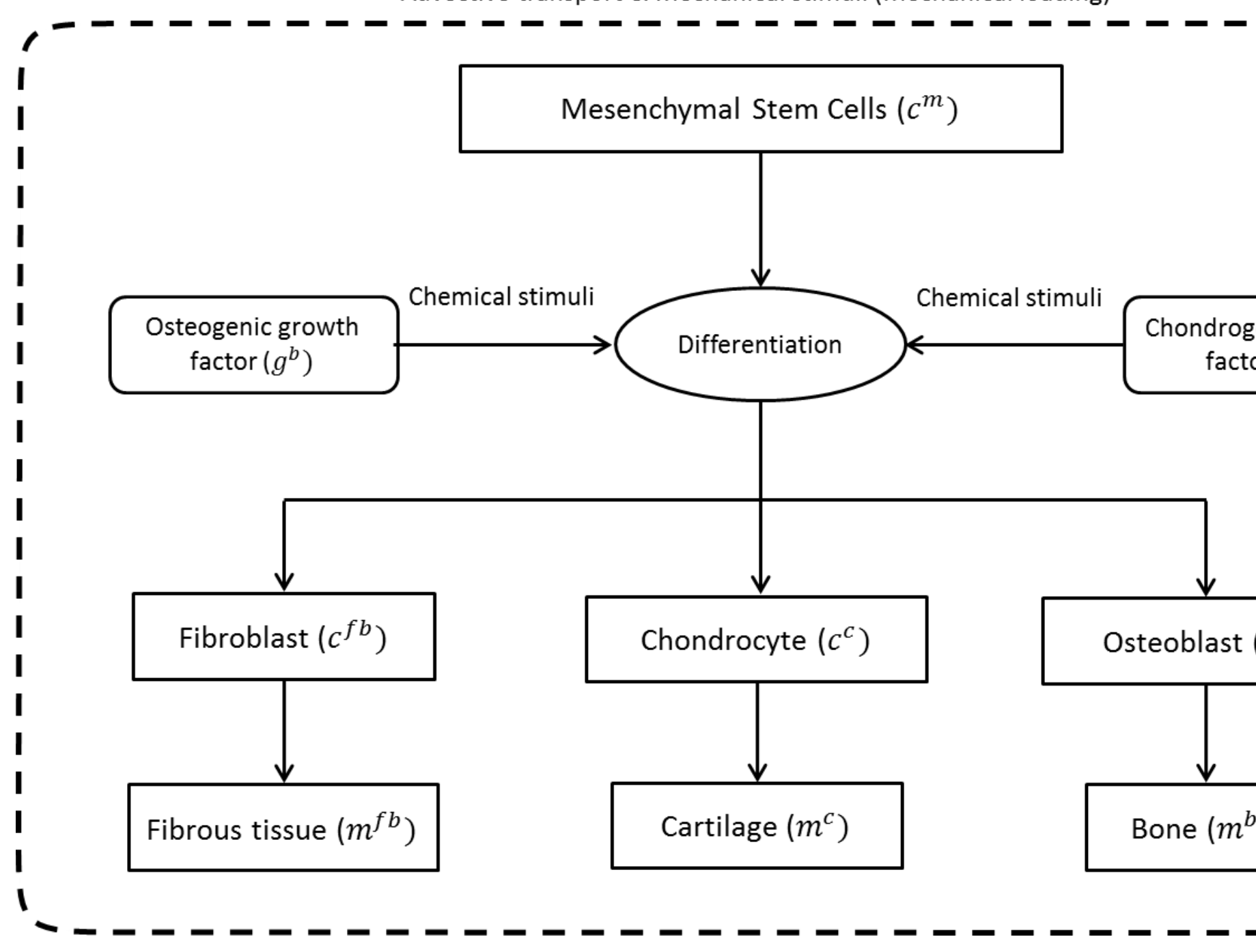

Fig. 10 A schematic overview of the model proposed in this study 


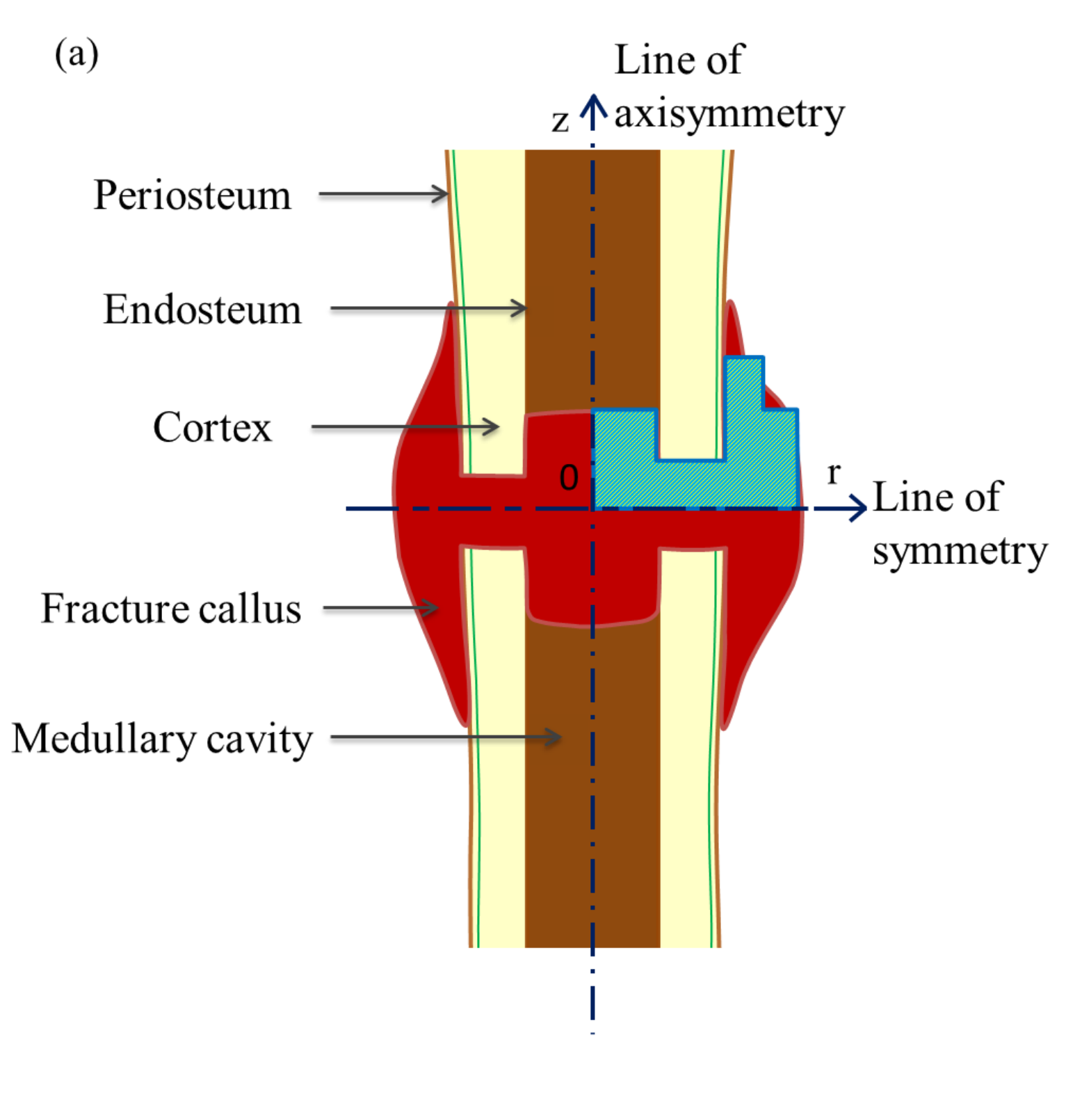




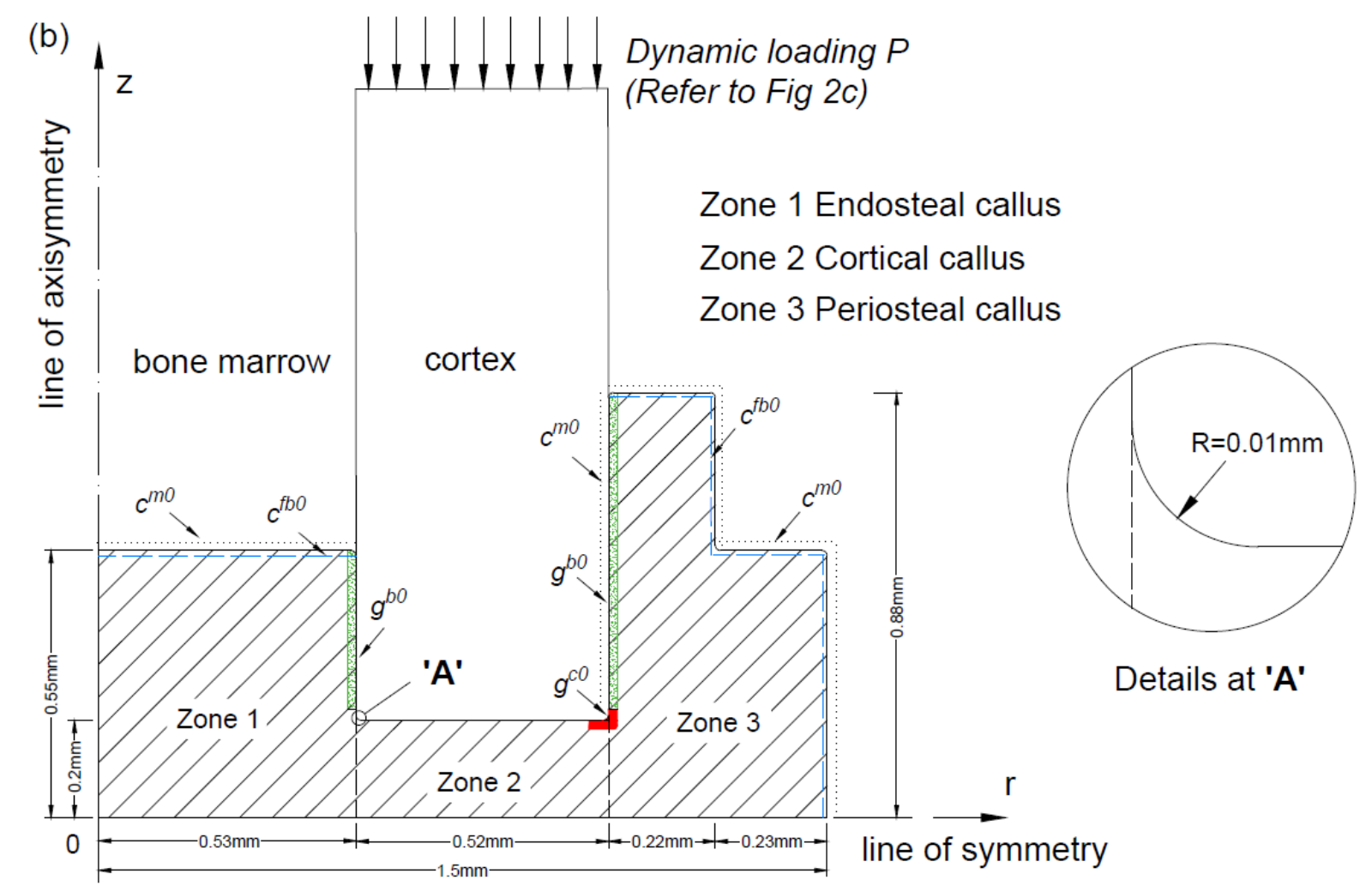

Mesenchymal Stem Cells $\left(c^{m 0}\right) \quad$ Chondrogenic growth factor $\left(g^{c 0}\right)$ Fibroblast $\left(C^{f b 0}\right)$

Osteogenic growth factor $\left(g^{b 0}\right)$ 
(c)

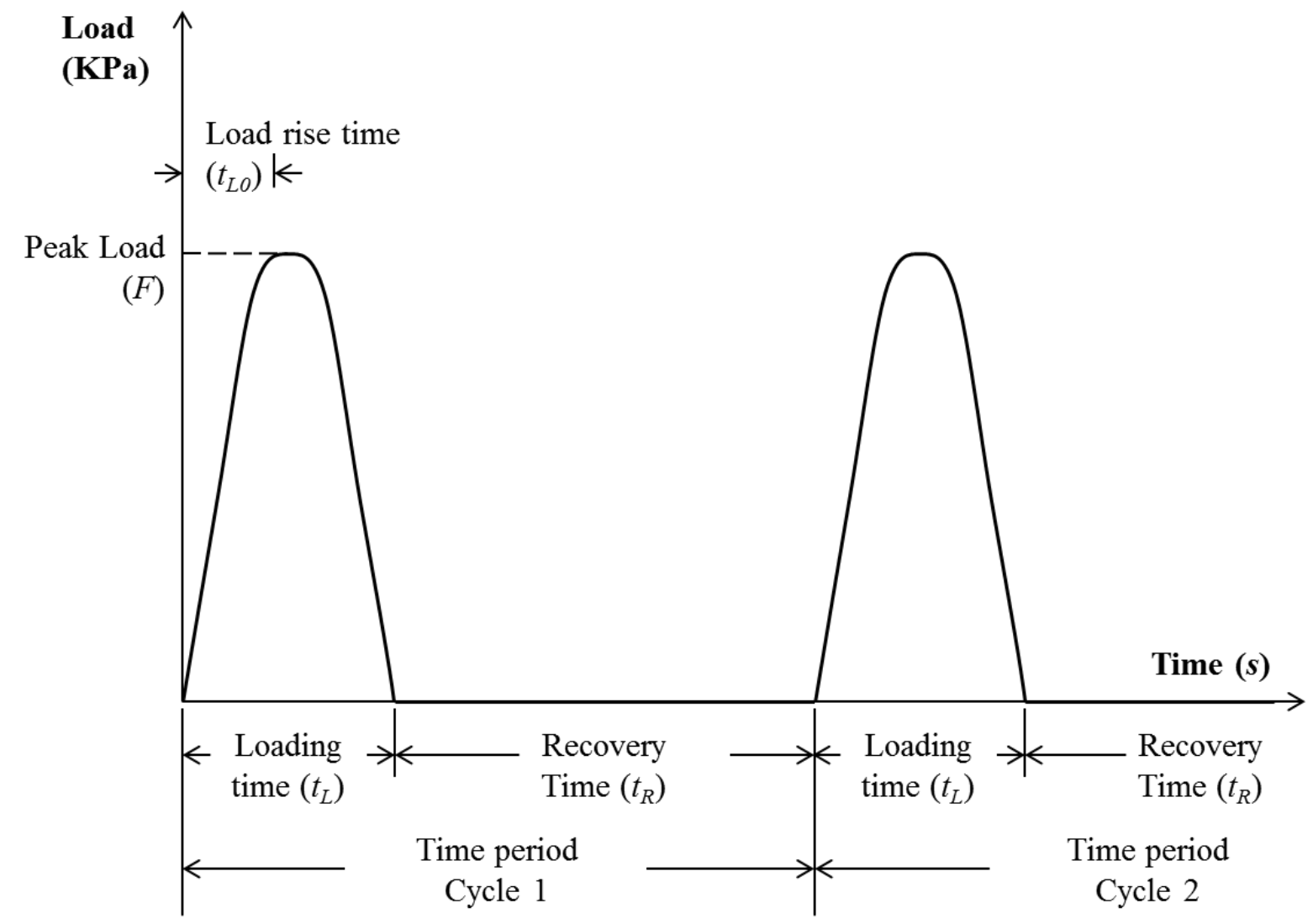

Fig. 2 (a) Schematic diagram of coronal section of a fractured femur; (b) Fracture callus domain of rodent femur, with dimensions adopted from Geris, Gerisch, Sloten, Weiner and Oosterwyck 16. $c^{m 0}, c^{f b 0}, g^{c 0}$ and $g^{b 0}$ are the boundary conditions of MSCs $\left(c^{m}\right)$, fibroblasts $\left(c^{f b}\right)$, chondrogenic growth factor $\left(g^{c}\right)$, and osteogenic growth factor $\left(g^{b}\right)$ respectively. The inset diagram ' $A$ ' shows rounded corner geometry adopted along broken edges of cortex and callus borders with a filler of radius $(R) 0.01 \mathrm{~mm}$; and $(c)$ Loading protocol used in this study ${ }^{5,55}$. Each loading cycle consists of loading phase $\left(t_{L}\right)$ and recovery phase $\left(t_{R}\right)$ (i.e. time period $T=t_{L}+$ $t_{R}$ ) and a peak load (F) 

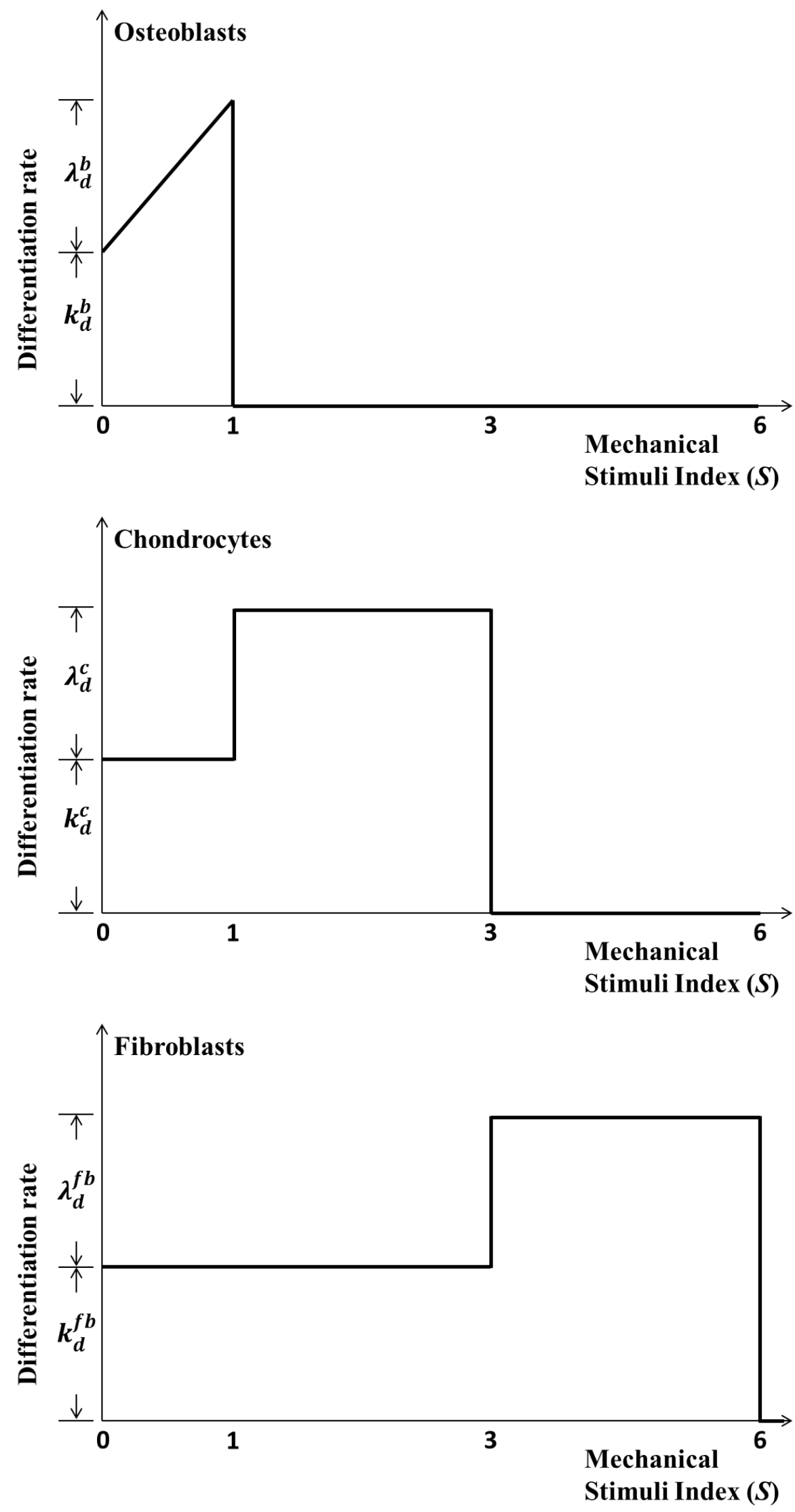

Fig. 3 Representative cell differentiation rate due to chemical stimuli and mechanical stimuli based on mechanical stimuli index $(S)^{1,36}$. This is based on the concept that 
if the level of mechanical stimuli is unfavourable, the differentiation rate of MSCS into that cell type is completely inhibited ${ }^{4}$
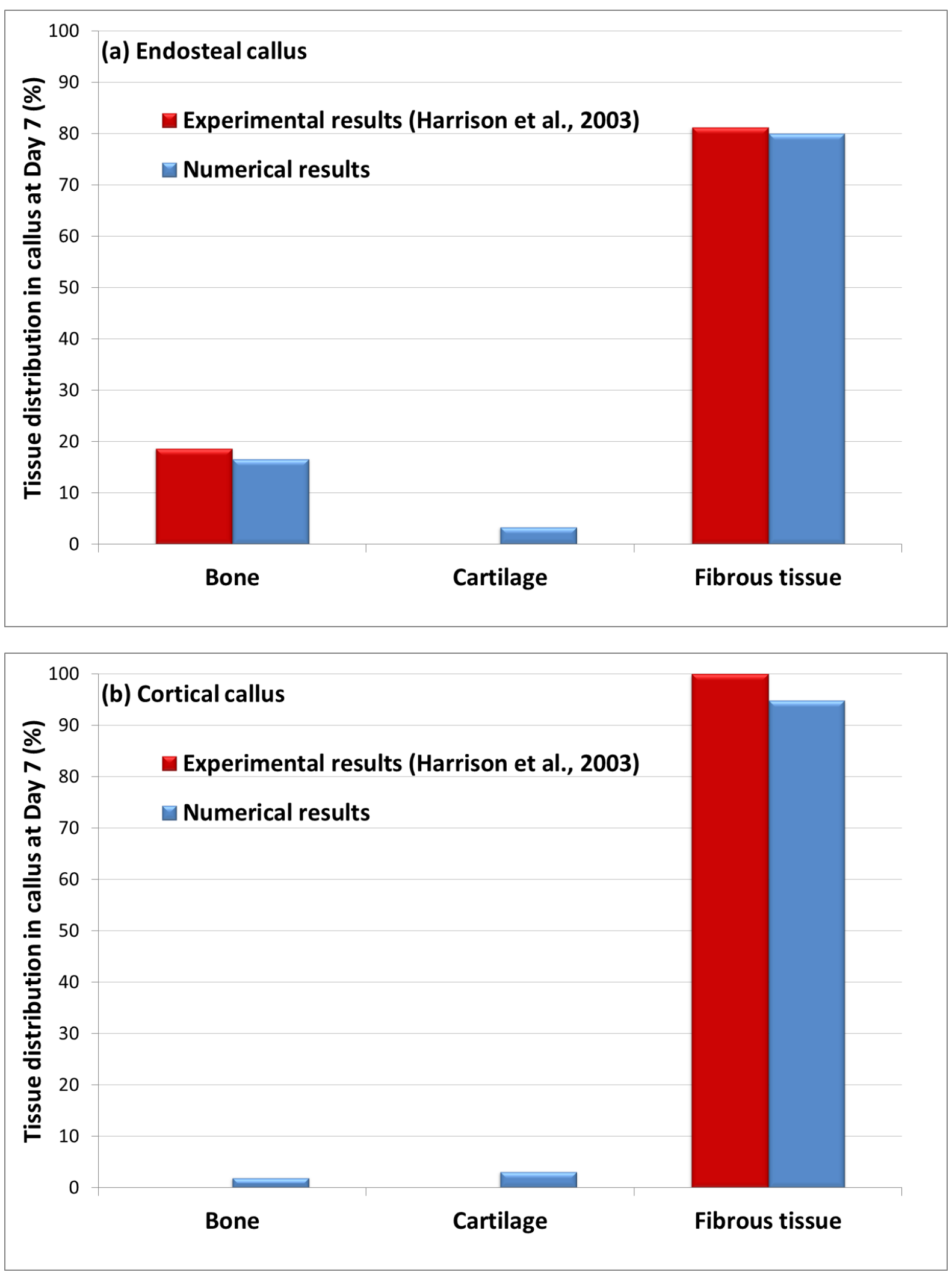


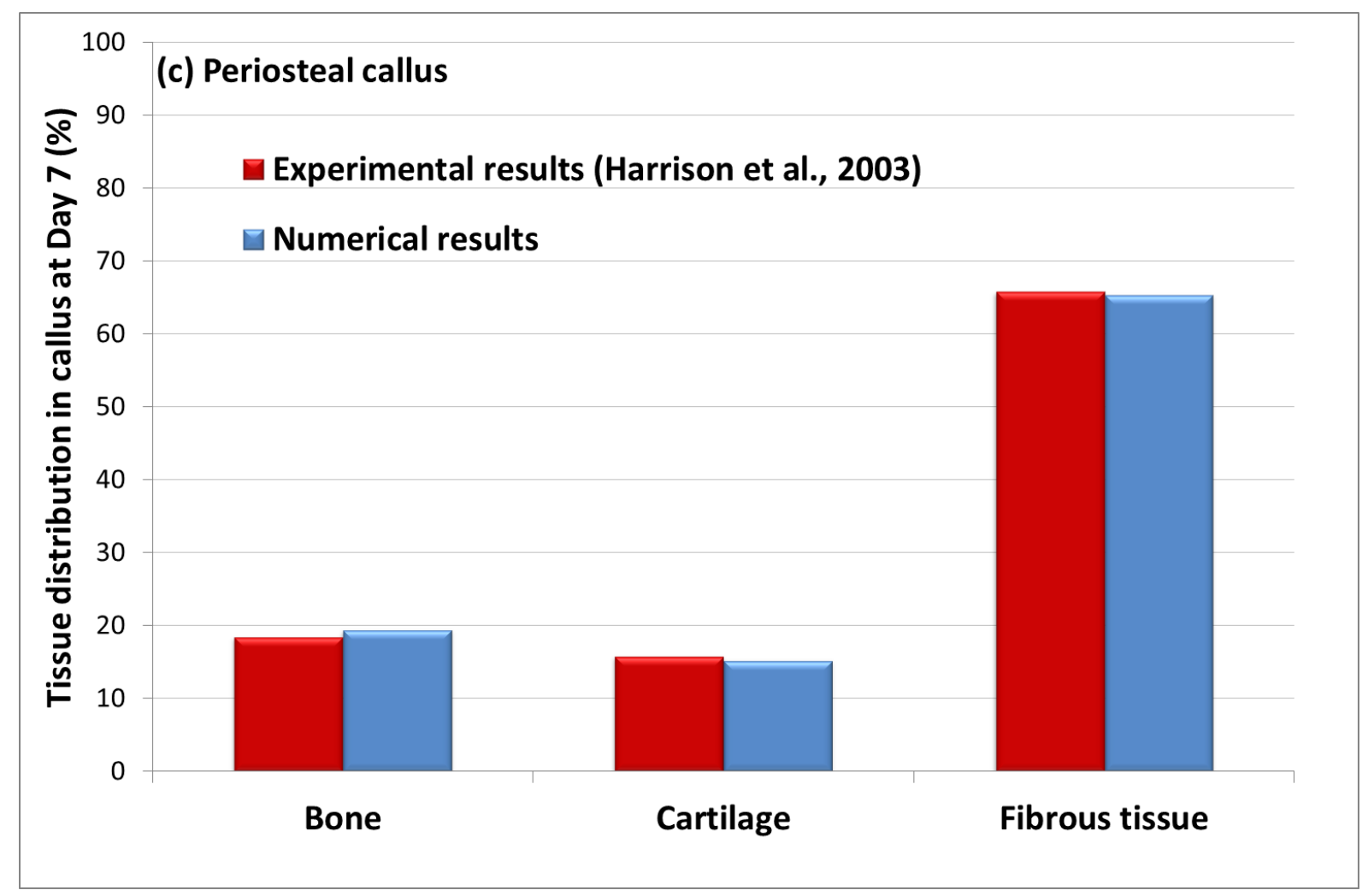

Fig. 4 Comparison of model prediction of callus tissue differentiation with experimental results of Harrison, Cunningham, Strömberg and Goodship 22. (a) Endosteal callus; (b) Cortical callus; and (c) Periosteal callus 

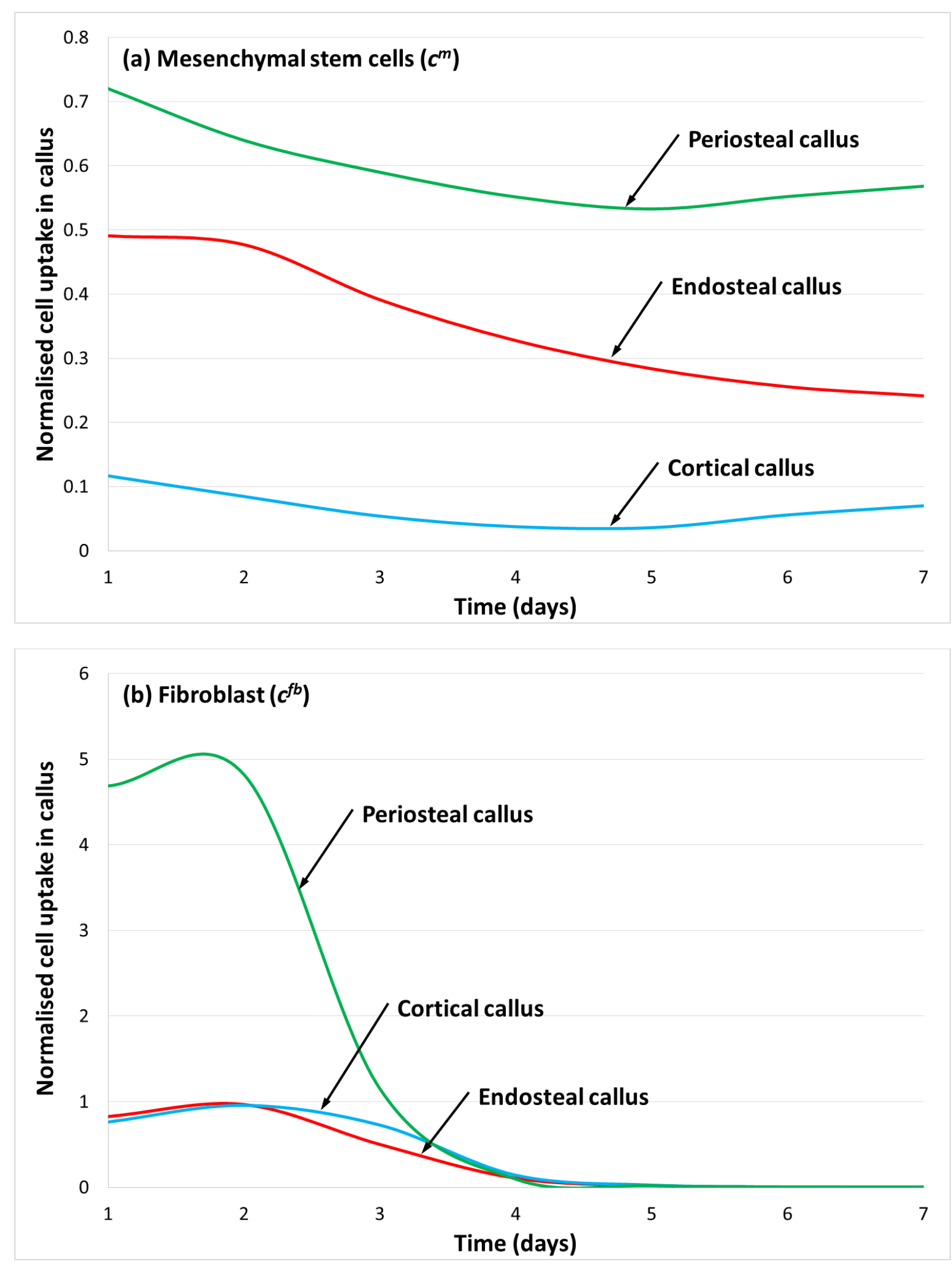


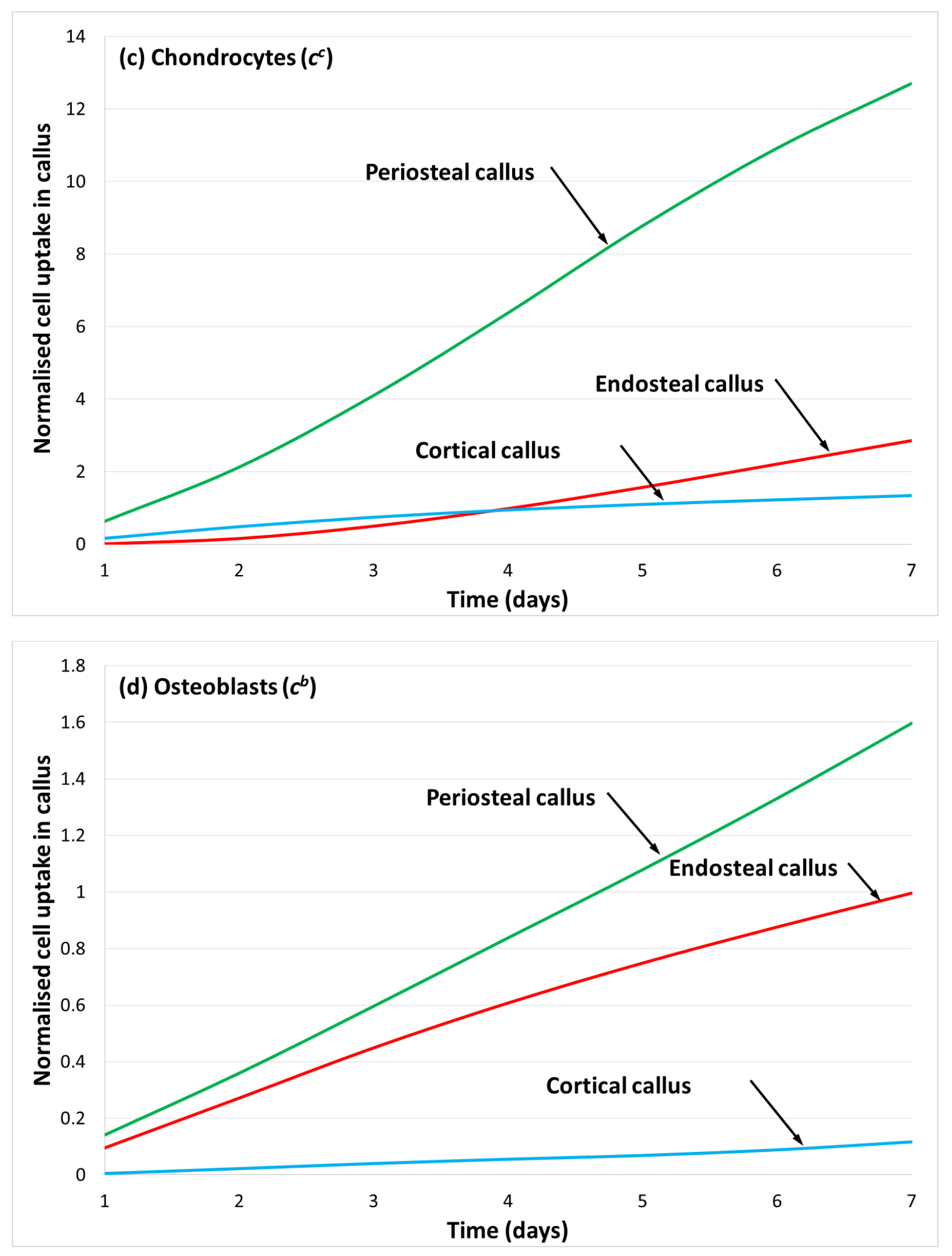



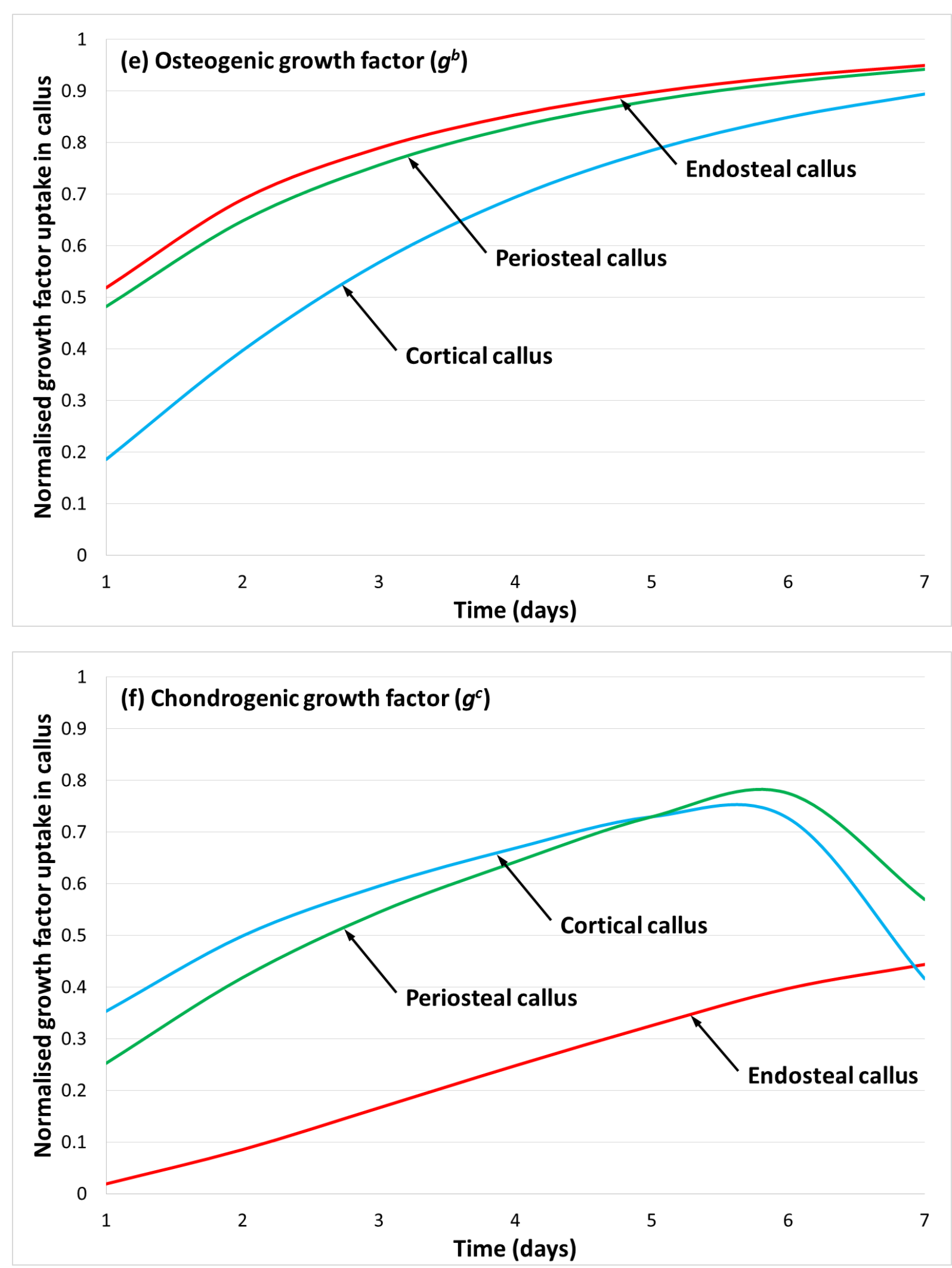

Fig. 5 Normalised time dependent cell uptake in fracture callus under free diffusion across different callus regions (a) MSCs $\left(c^{m}\right) ;(\boldsymbol{b})$ Fibroblasts $\left(c^{f b}\right) ;(\boldsymbol{c})$ Chondrocytes $\left(c^{c}\right) ;(\boldsymbol{d})$ Osteoblasts $\left(c^{b}\right)$; $(\boldsymbol{e})$ Osteogenic growth factor $\left(g^{b}\right)$; and $(\boldsymbol{f})$ Chondrogenic growth factor $\left(g^{c}\right)$. MSCs and fibroblasts are normalised to their boundary values (i.e. $c^{m 0}$ and $\left.c^{f b 0}\right)$ respectively, while chondrocytes and osteoblasts are normalised to the boundary 
conditions of stem cells (i.e. $\left.c^{m 0}\right)$. Growth factors $g^{b}$ and $g^{c}$ are normalised to their boundary conditions (i.e. $g^{b 0}$ and $g^{c 0}$ ), respectively.

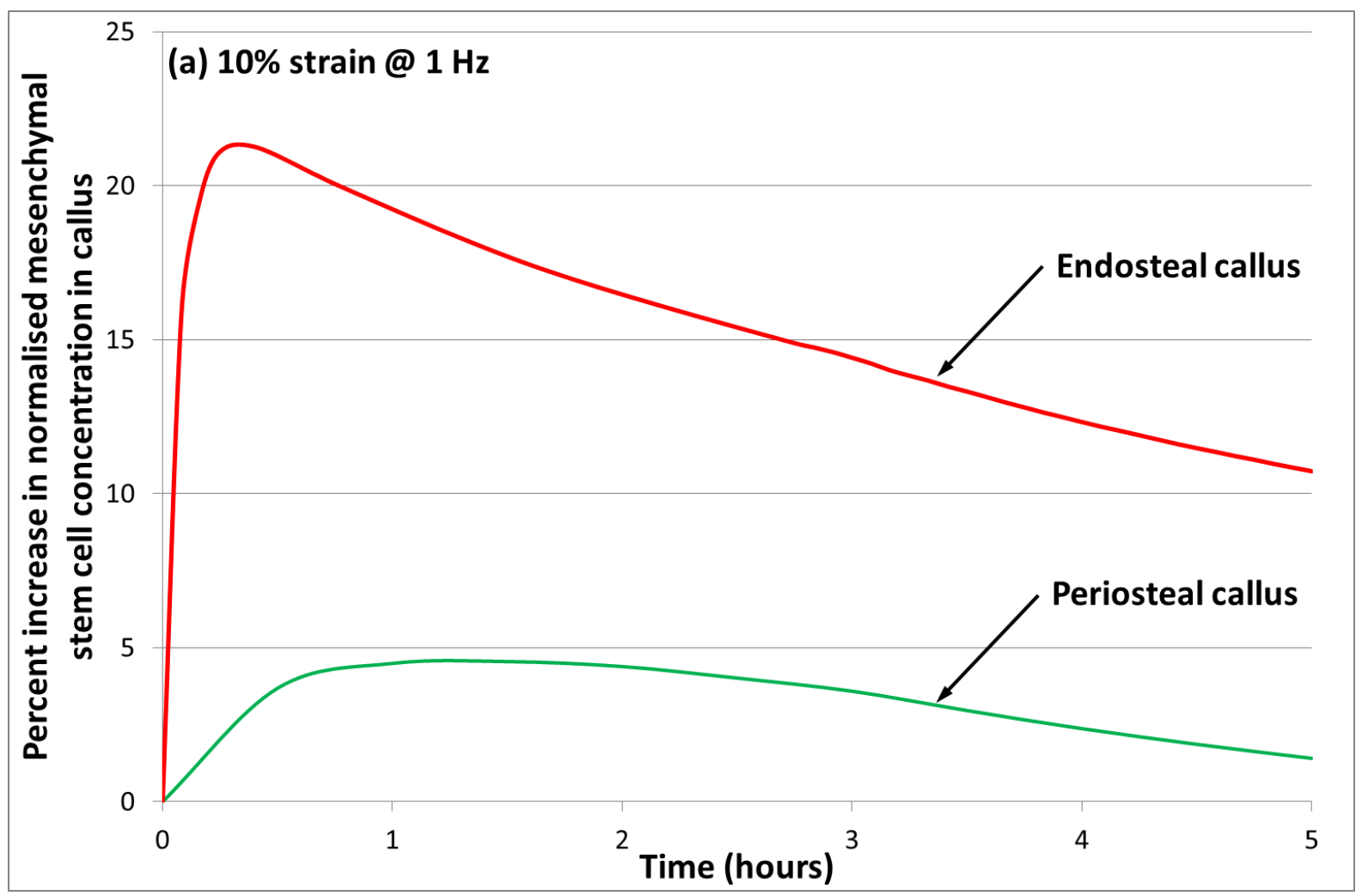




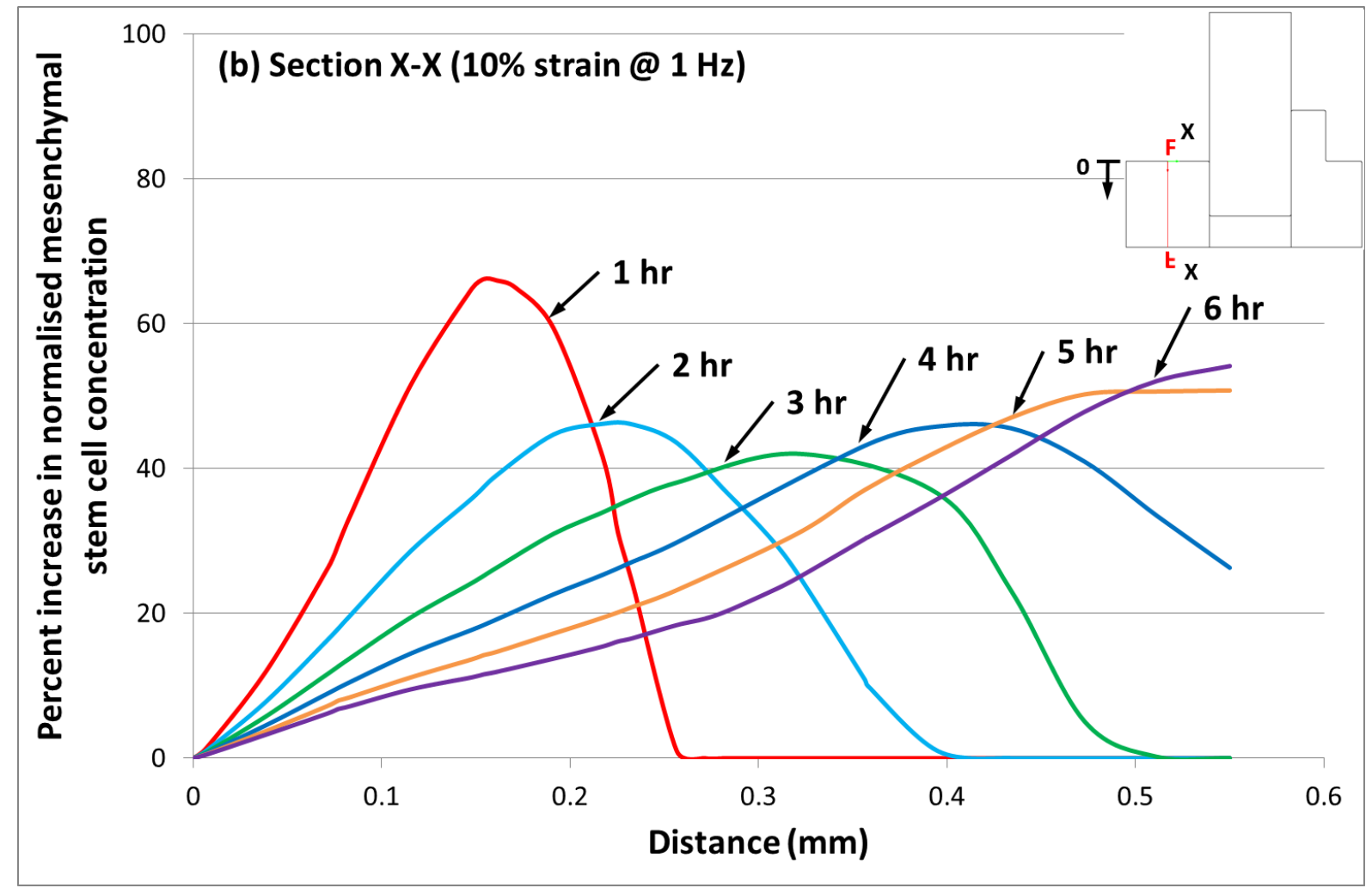

Fig. 6 Percent increase in normalised mesenchymal stem cell concentration under dynamic loading in comparison to free diffusion. (a) Time dependent stem cell concentration; and (b) spatial dependent stem cell concentration at Section $X-X$ 

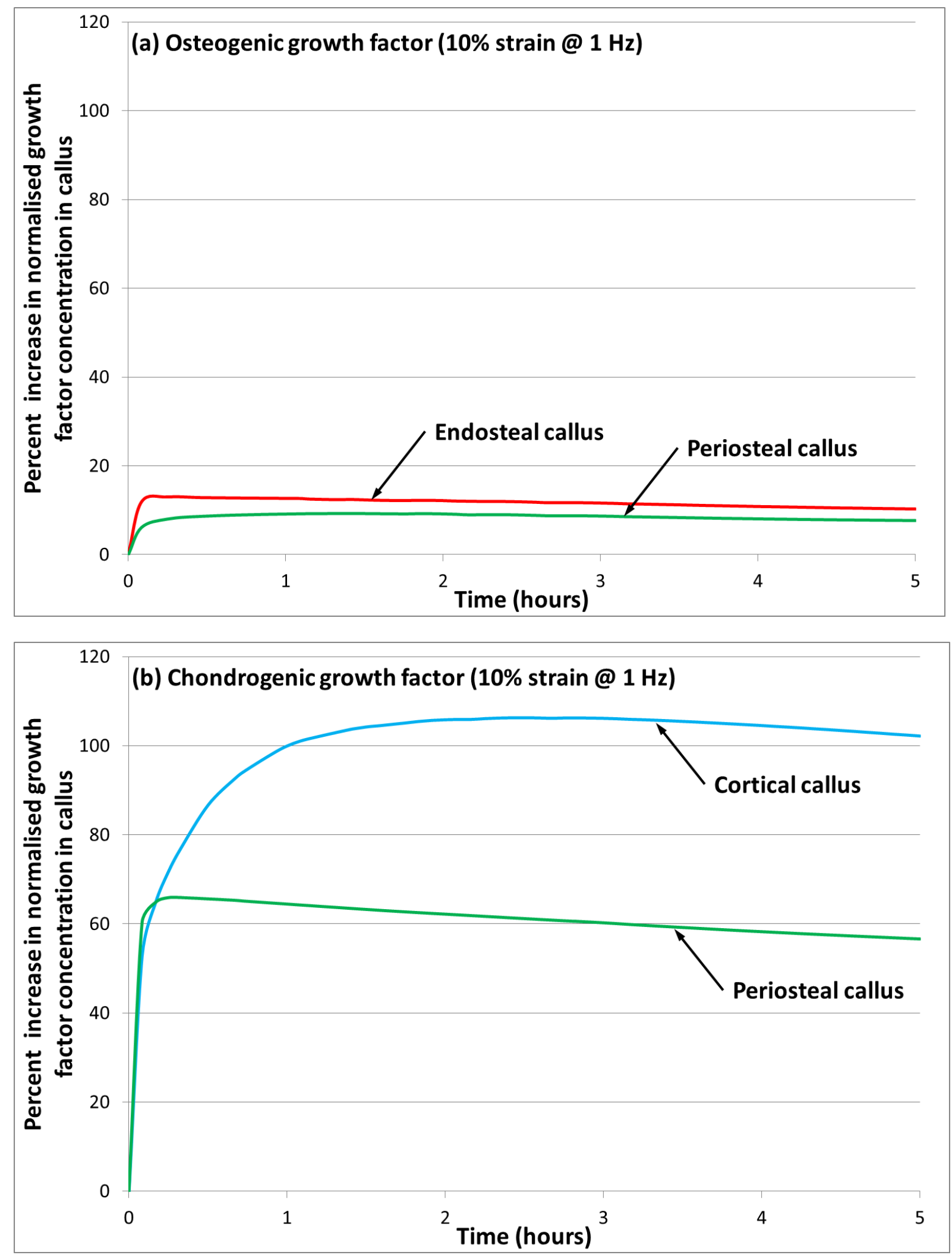

Fig. 7 Percent increase in normalised growth factor concentration under dynamic loading in comparison to free diffusion across different callus regions. (a) Osteogenic growth factor $\left(g^{b}\right)$; and (b) Chondrogenic growth factor $\left(g^{c}\right)$ 

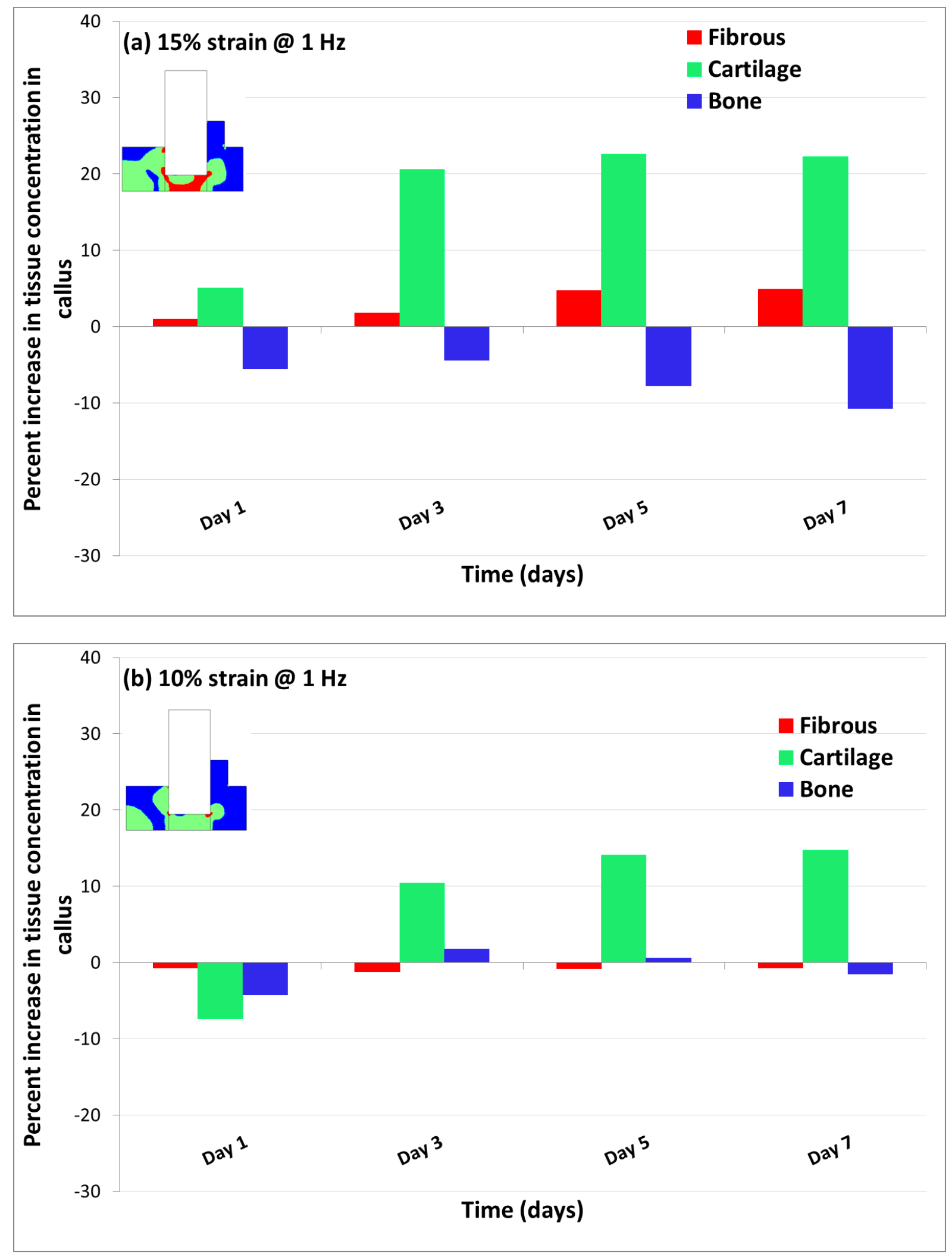

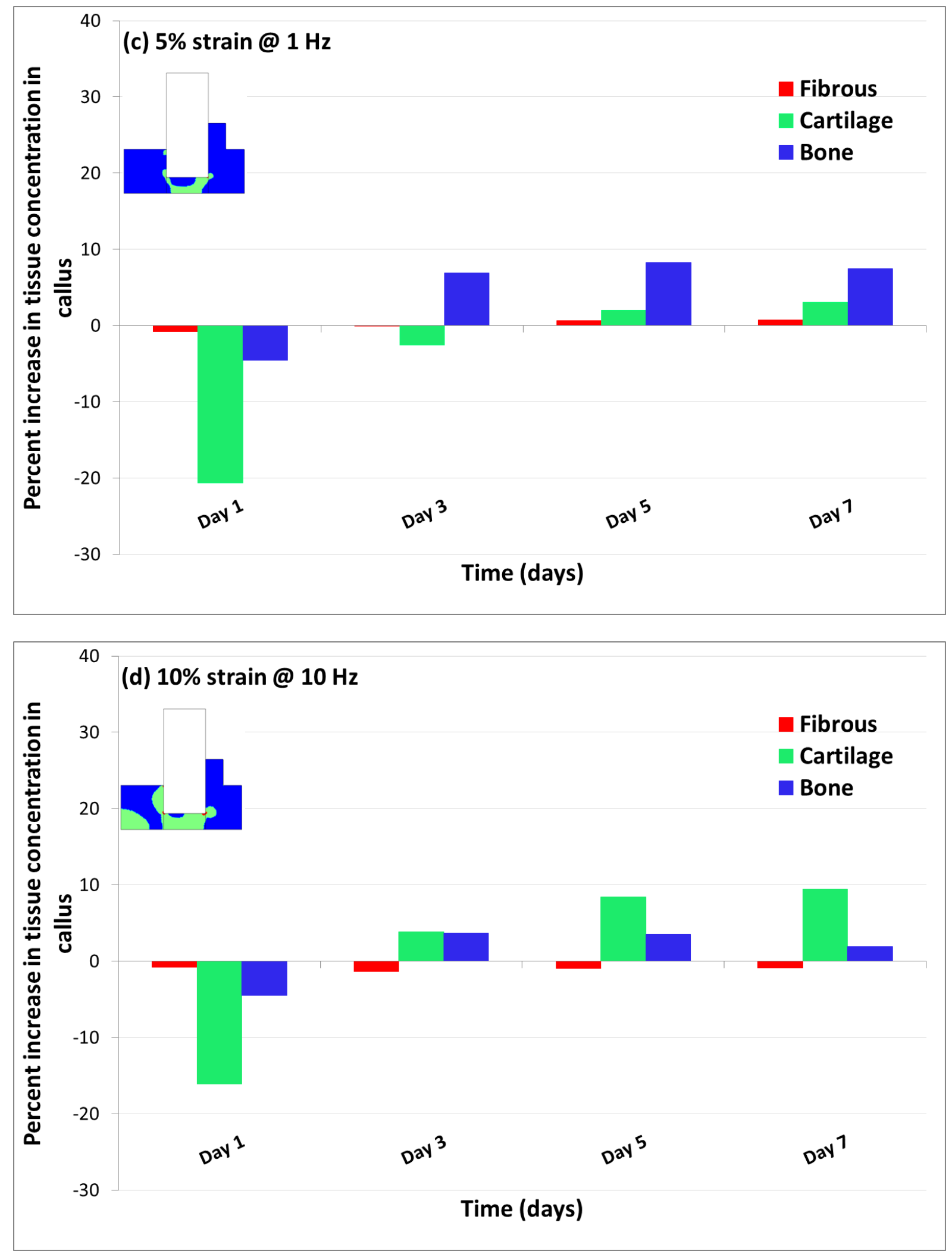

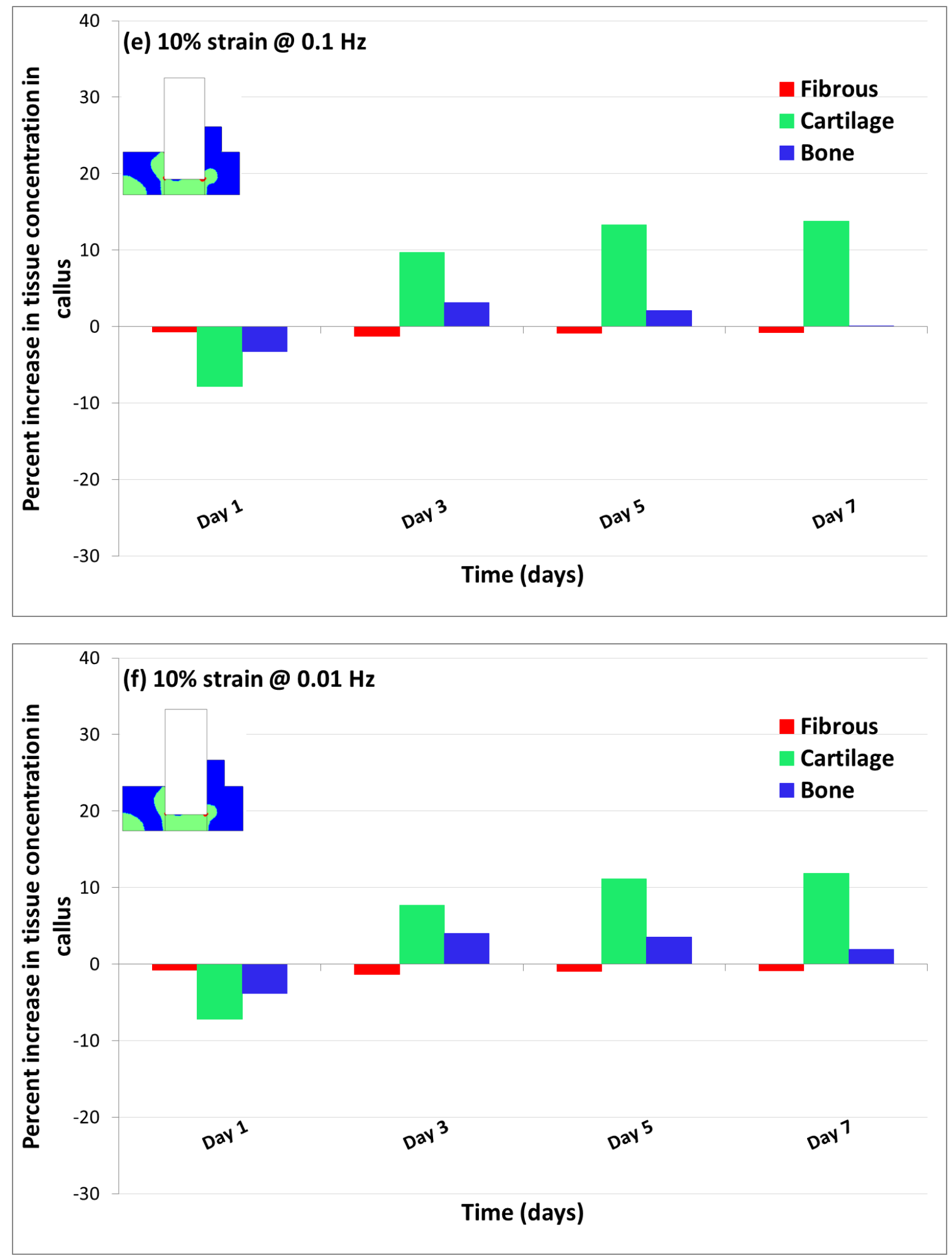

Fig. 8 Percent change in fibrous tissue, cartilage and bone concentration in callus under different loading conditions relative to control (i.e. free diffusion). Each inset diagram shows spatial distribution of actual tissue concentration under corresponding loading conditions. 

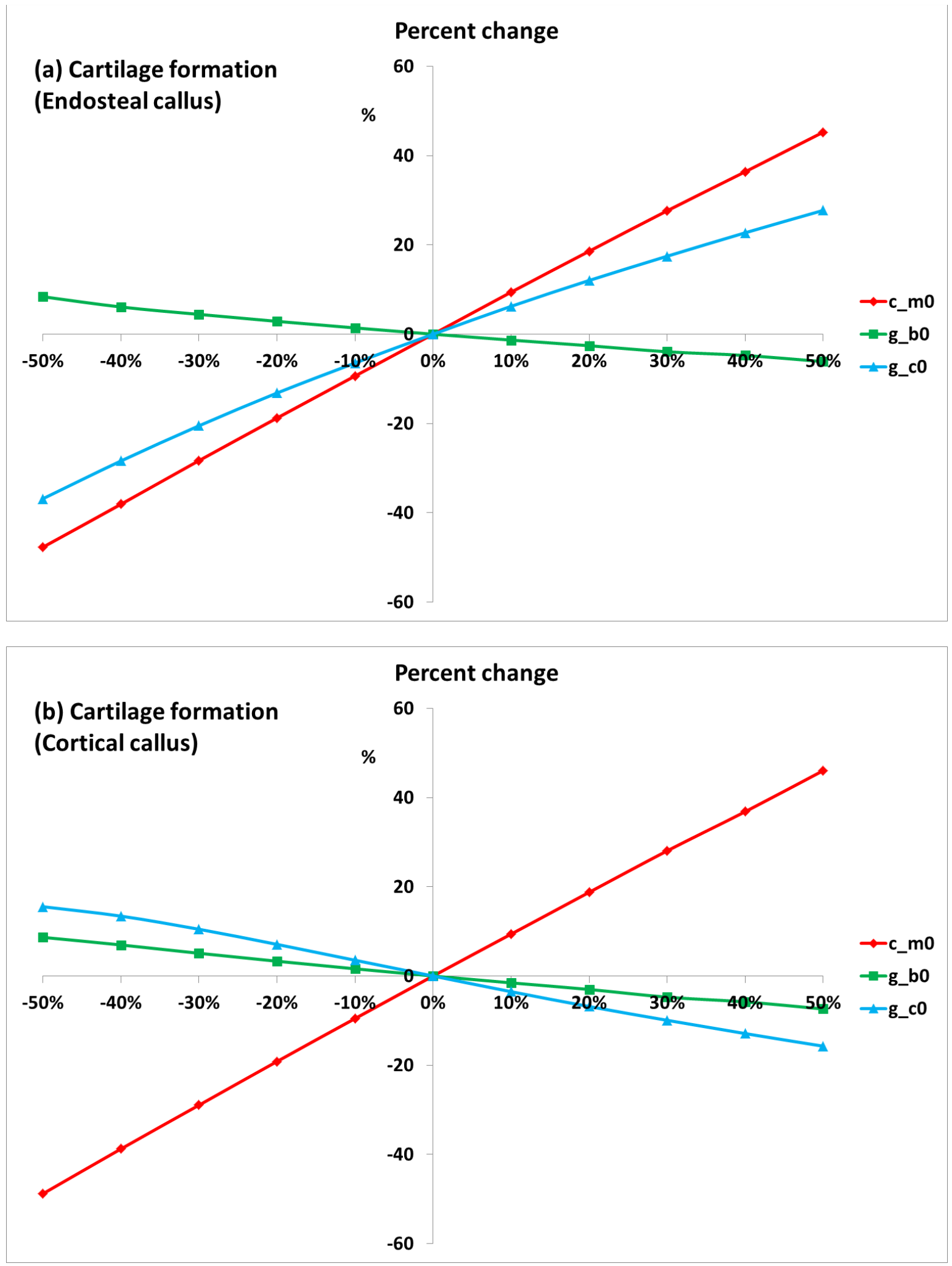

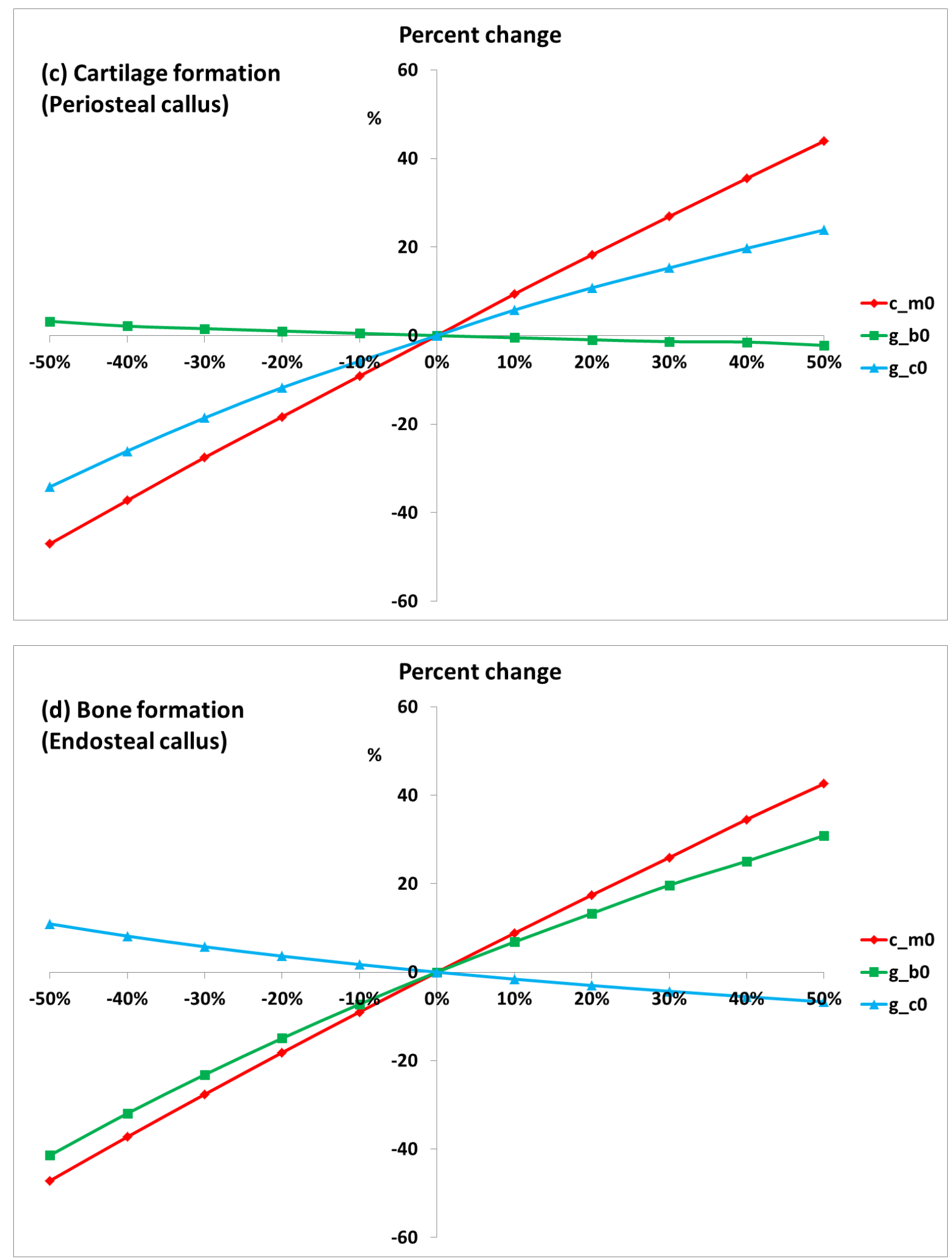

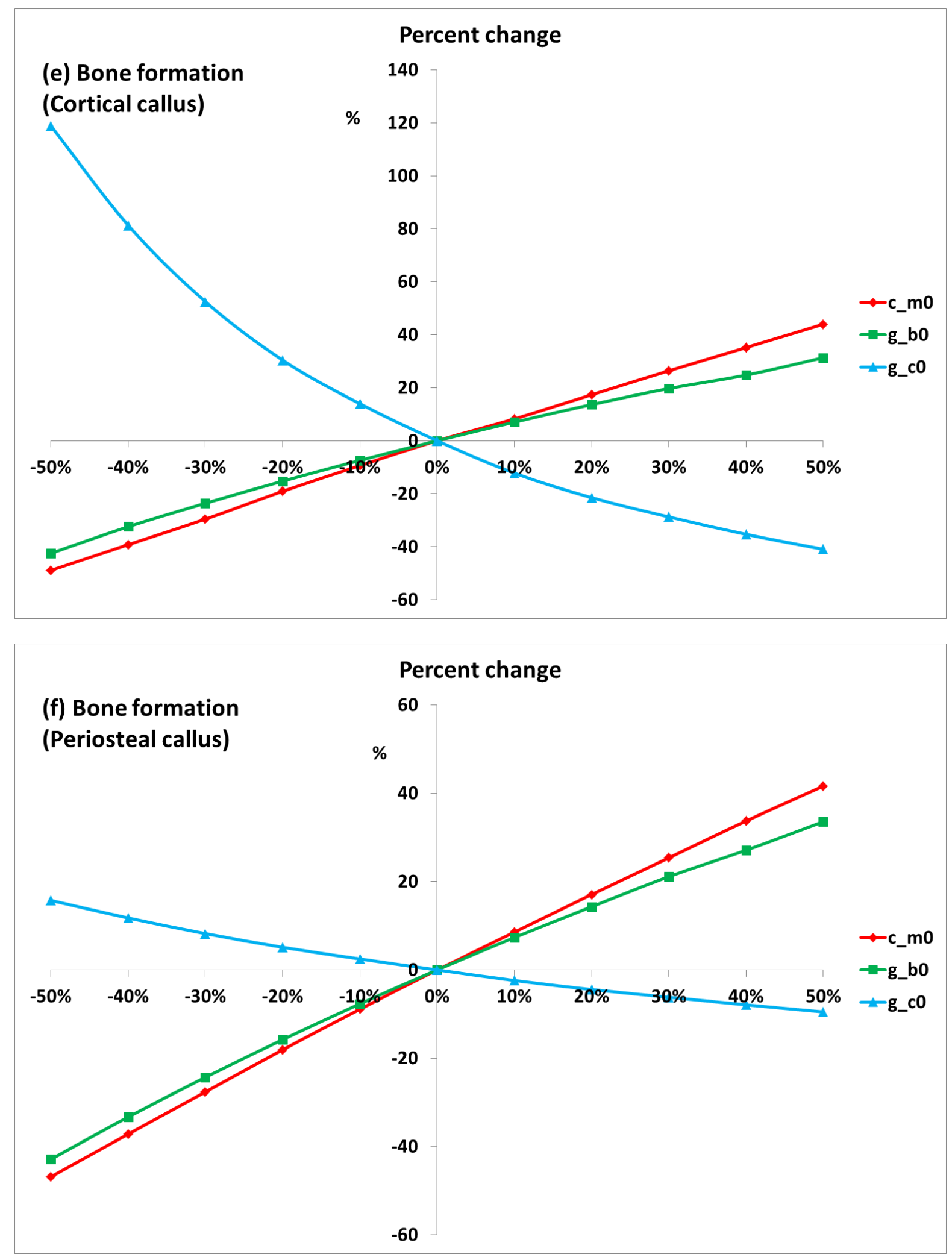

Fig. 9 Sensitivity analyses of the initial boundary conditions of mesenchymal stem cells $\left(c^{m 0}\right)$, osteogenic growth factor $\left(g^{b 0}\right)$ and chondrogenic growth factor $\left(g^{c 0}\right)$ on tissue formation. 


\section{University Library}

\section{- M M N E R VA A gateway to Melbourne's research publications}

Minerva Access is the Institutional Repository of The University of Melbourne

\section{Author/s:}

Ghimire, S;Miramini, S;Richardson, M;Mendis, P;Zhang, L

Title:

Role of Dynamic Loading on Early Stage of Bone Fracture Healing

Date:

2018-11-01

Citation:

Ghimire, S., Miramini, S., Richardson, M., Mendis, P. \& Zhang, L. (2018). Role of Dynamic Loading on Early Stage of Bone Fracture Healing. ANNALS OF BIOMEDICAL ENGINEERING, 46 (11), pp.1768-1784. https://doi.org/10.1007/s10439-018-2083-X.

Persistent Link:

http://hdl.handle.net/11343/282736 